OPEN ACCESS

Edited by:

Eldon R. Rene,

IHE Delft Institute for Water Education,

Netherlands

Reviewed by:

Renliang Huang,

Tianjin University, China

Jia Chu,

Xi'an University of Science and

Technology, China

*Correspondence:

Huey Ling Tan

hueyling@uitm.edu.my

Specialty section: This article was submitted to

Bioenergy and Biofuels,

a section of the journal

Frontiers in Energy Research

Received: 06 November 2020 Accepted: 08 February 2021

Published: 26 April 2021

Citation:

Khairol Anuar NK, Tan HL, Lim YP, So'aib MS and Abu Bakar NF (2021) A

Review on Multifunctional CarbonDots Synthesized From Biomass

Waste: Design/ Fabrication,

Characterization and Applications.

Front. Energy Res. 9:626549.

doi: 10.3389/fenrg.2021.626549

\section{A Review on Multifunctional Carbon-Dots Synthesized From Biomass Waste: Design/ Fabrication, Characterization and Applications}

\author{
Nurul Kamilah Khairol Anuar ${ }^{1}$, Huey Ling Tan ${ }^{1 *}$, Ying Pei Lim ${ }^{1}$, Mohamad Sufian So'aib ${ }^{2}$ and \\ Noor Fitrah Abu Bakar ${ }^{1}$
}

${ }^{1}$ Faculty of Chemical Engineering, Universiti Teknologi MARA, Shah Alam, Malaysia, ${ }^{2}$ Faculty of Chemical Engineering, Universiti Teknologi MARA, Cawangan Pulau Pinang, Permatang Pauh, Malaysia

Carbon-Dots (C-Dots) have drawn much attention in recent years owing to their remarkable properties such as high biocompatibility, low toxicity, nano-scale size, and ease of modification with good tuneable photoluminescence performance. These unique properties have led C-Dots to become a promising platform for bioimaging, metal ion sensing and an antibacterial agent. C-Dots can be prepared using the top-down and bottom-up approaches, in which the latter method is commonly used for large scale and low-cost synthesis. C-Dots can be synthesized using sustainable raw materials or green biomass since it is environmentally friendly, in-expensive and most importantly, promotes the minimization of waste production. However, using biomass waste to produce highquality C-Dots is still a matter of concern waiting for resolution, and this will be the main focus of this review. Fundamental understanding of C-Dots such as structure analysis, physical and chemical properties of C-Dots, various synthesis methodology and type of raw materials used are also discussed and correlated comprehensively. Additionally, factors affecting the bandgap of the C-Dots and the strategies to overcome these shortcomings are also covered. Moreover, formation mechanism of C-Dots focusing on the hydrothermal method, option and challenges to scale up the C-Dots production are explored. It is expected that the great potential of producing C-Dots from agricultural waste a key benefit in view of their versatility in a wide range of applications.

Keywords: biomass waste, bandgap tuning, carbon dots, green synthesis, sustainable raw materials, fabrication parameters

\section{INTRODUCTION}

Carbon-based nanostructures have extended colossal designation in the field of material science employed by the researchers since it has been reported in 2004 by Xu et al. who has accidentally discovered carbon dots (C-Dots) as the new addition to the carbon family when using arc discharge to synthesize single-walled carbon nanotubes (CNTs) (Xu et al., 2004). In general, carbon-based nanomaterial structures are classified into zero dimension like fullerene, diamond crystals and carbon dots; one dimension carbon nanotubes (CNTs) or rolled up graphene sheets (as they are likely to unroll and form graphene) (Qu et al., 2013). In addition, graphene quantum dots (GQDs) and graphene oxide are examples of two-dimensional nanomaterials (Demchenko and Dekaliuk, 2013). 
The latest semiconductor nanocarbon components consist of carbon dots (C-Dots) or carbon quantum dots (CQDs) (Raveendran et al., 2019) with particle size less than $10 \mathrm{~nm}$ (Sagbas and Sahiner, 2019). C-Dots have "nearly spherical shapes" (Tan et al., 2014) and are known to have an amorphous or crystalline core with predominant $\mathrm{sp}^{2}$ carbon and an oxidized carbon surface with a carboxyl group (Liu et al., 2017). Recently, C-Dots have evoked tremendous interests in researchers as a potential candidate to substitute toxic metal-based quantum dots (QDs). The high toxicity of heavy metal-based semiconductor quantum dots seems to limits both biological and environmental applications due to its impact on the environment and human health (Reiss et al., 2016). C-Dots were reported to have good biocompatibility, less toxicity (Wang and $\mathrm{Hu}, 2014$ ), high photoluminescence (PL) intensity (Sabet and Mahdavi, 2019), high chemical stability (Atchudan et al., 2017) and possesses excellent biological, physical and chemical properties, thus have great potential in various applications (Liu et al., 2017; Bhatt et al., 2018).

The variety of synthetic approaches for C-dots can be categorized into two main routes: top-down and bottom-up method (Chan et al., 2018), including laser ablation, arc discharge, electrochemical approach, microwave irradiation, direct pyrolysis, and hydrothermal reaction (De and Karak, 2017). Among all the methods used to synthesize C-Dots, hydrothermal treatment is the most popular approach because the synthesis process is simple, clean and economical (Chan et al., 2018). In this method, the carbon-yielding compounds are subjected to a mild experiment condition (Sabet and Mahdavi, 2019) and biomass waste can be used to synthesize the C-Dots. There are three types of biomass resources: organism, waste materials and protein products. Carbon sources from renewable and waste materials are inexpensive and sustainable, thus an ideal material for the synthesis of C-Dots (Hu et al., 2014). Different types of wastes had been set as a sustainable green precursor to obtaining C-Dots throughout the years which includes sago waste (Tan et al., 2014), mint leaf (Raveendran et al., 2019), orange waste peel (Prasannan and Imae, 2013), banana plant stem (Vandarkuzhali et al., 2017), waste frying oil (Hu et al., 2014), etc. Other C-Dots precursors derived from biomass are shown in Figure 1. The selection of carbon-rich waste from recycling and reuse as starting materials to produce C-Dots will be beneficial to create an ecological community through waste minimization (Tan et al., 2014).

While several C-Dots have been synthesized from large raw materials, synthesizing C-Dots with prevailing performance such as broad photoluminescence and controllable surface groups is still difficult. The development of cost-effective and highly efficient bottom-up fabrication techniques, in particular, promotes wide-range C-Dots synthesis and investigation, thus makes it difficult to reveal the consistency of the structure and photoluminescence process in different systems. The goal of this review report is therefore to evaluate the properties of the C-Dots, focusing on the fabrication of C-Dots, characterization methods, as well as applications of C-Dots, prepared using various forms of biomass as carbon sources. A critical evaluation alongside an inclusive review of improvement in the fundamental understanding of C-Dots including structure analysis, physical and chemical properties of C-Dots, are also discussed and correlated comprehensively. In addition, factors affecting the bandgap of the C-Dots and the strategies to overcome these shortcomings are also covered. Moreover, formation mechanism of C-Dots from biomass, option to scale up the C-Dots production and the challenges in large scale synthesis are discussed comprehensively. It is expected that the great potential of producing C-Dots from agricultural waste the key benefit in view of their versatility in a wide range of applications.

\section{STRUCTURE AND MORPHOLOGY OF C-DOTS}

In general, C-Dots consist of mainly carbon skeleton with two other fundamental elements such as hydrogen and oxygen with different ratios in the C-Dots (Bhartiya et al., 2016; Zhao et al., 2015). They can be found mostly amorphous spherical shape consisting of both $\mathrm{sp}^{2}$ and $\mathrm{sp}^{3}$ hybridized carbon atoms with sizes of less than $10 \mathrm{~nm}$ (Sciortino et al., 2018). C-Dots are different with graphene quantum dots (GQDs) that only consist of $\mathrm{sp}^{2}$ hybridized carbon packed into two-dimensional honeycomb lattice (Qu et al., 2013). Different species of carbon-based materials formation depend on the different precursor and synthesis methods when fabricating the C-Dots (Liu et al., 2019). With polar groups such as carboxyl and carbonyl groups, the C-Dots surface can be richly modified. Basic graphene, graphene oxide and C-Dots are schematically presented in Figure 2.

\section{BIOCOMPATIBILITY}

The biocompatibility and small toxicity are two important properties that enable biological applications. According to $\mathrm{Bi}$ et al., extracted C-Dots have almost no toxicity which is safe and theoretically high biocompatibility at a dosage $20 \mathrm{mg} \mathrm{L}^{-1}$ (Bi et al., 2017). Most of the C-Dots possess low toxicity when the concentration of the C-Dots is as low as $2.5 \mathrm{mg} \mathrm{ml}^{-1}$ (Kang et al., 2015) or $1 \mathrm{mg} \mathrm{ml}^{-1}$ (Dias et al., 2019) as indicated by some cytotoxicity studies. However, there is an instance where a high concentration (e.g., $100 \mathrm{mg} \mathrm{L}^{-1}$ ) of the C-Dots that shows minimal toxicity (Kavitha and Kumar, 2018). This shows that C-Dots demonstrated minor toxicity at different concentrations which cause a negligible loss in cell viability and excellent biocompatibility for novel biological applications (Liu et al., 2019). Although C-Dots have been claimed to have low toxicity but according to the study by Dias et al. (2019), the toxicity of C-dots depends primarily on the extraction process such as the type of the carbon source used and the synthesis conditions (temperature, time) (Pierrat et al., 2015; Dias et al., 2019).

\section{CHARACTERIZATION OF C-DOTS}

\section{TEM and HRTEM Analysis}

Extensive studies have been recently reported on C-Dots characterization to better understand the unique properties of 


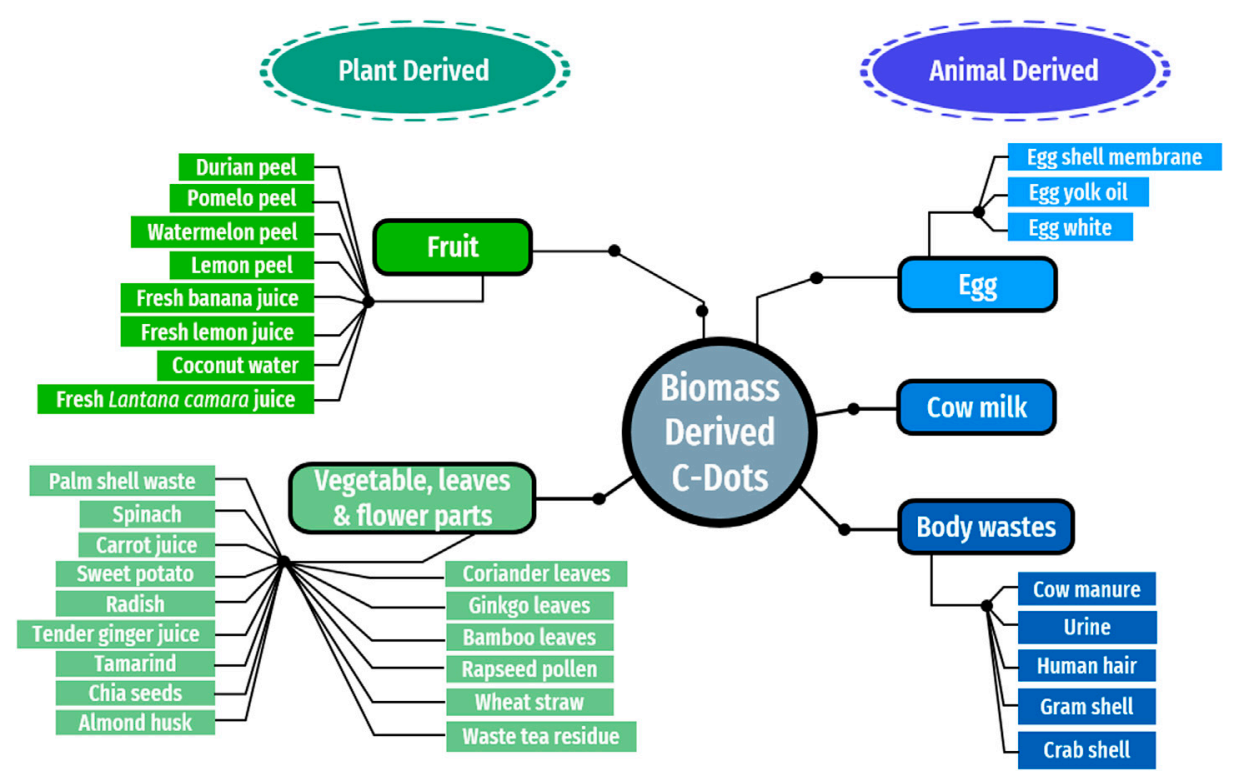

FIGURE 1 | C-Dots precursors from biomass.

the C-Dots. Transmission Electron Microscopy (TEM) analysis can be used to determine the size and shape of the C-Dots which has an average size of below $10 \mathrm{~nm}$ (Wang et al., 2020). The latter was evident by TEM images of C-Dots monodispersion in water (from biomass waste) without apparent reunion (Wang et al., 2020) with a distinct lattice spacing of $0.21 \mathrm{~nm}$.

\section{XPS and FTIR Analysis}

Fourier-transform infrared spectroscopy (FTIR) and X-ray photoelectron spectroscopy (XPS) are used to examine the surface properties of the C-Dots. FTIR spectrum captures the functional groups in C-Dots while XPS detects the identities of the elements. C-Dots prepared from plant-based biomass waste such as ginkgo biloba leaves, paulownia leaves and magnolia flowers consists of various chemical composition such as $\mathrm{O}-\mathrm{H}$, N-H, C-H, C=O, C-N, C-O-C and C-S (Wang et al., 2020). The XPS findings can be used to evaluate the elements such as nitrogen and sulphur in the C-Dots and the stretching and bending vibration modes of bonding like- $\mathrm{OH},-\mathrm{COOH}$ and- $\mathrm{NH}_{2}$ between the elements in the C-Dots ( $\mathrm{Hu}$ et al., 2017). The presence of the hydrophilic groups $(-\mathrm{OH},-\mathrm{COOH}$ and- $\mathrm{NH}_{2}$ ) in the C-Dots indicate well dispersibility of C-Dots in the water as displayed by the TEM and HRTEM images.

\section{Raman and XRD Analysis}

Raman spectroscopy is commonly used in material recognition and spectral characteristics of molecular structures (Hu et al., 2017). Raman spectrum acquired using and C-Dots synthesized from sugarcane bagasse showed the presence of D-band and G-band ranging from $1,300-1,400 \mathrm{~cm}^{-1}$ and $1,500-1,650 \mathrm{~cm}^{-1}$ respectively. The results show two obvious peaks; a sharp intense peak of G-band $\left(1,580 \mathrm{~cm}^{-1}\right)$ and a weak peak of D-band $\left(1,361 \mathrm{~cm}^{-1}\right)$. G- and D-band intensities are derived respectively from their full spectrum peak counts while the $2 \mathrm{D}$ peak of $\mathrm{sp}^{2}$ hybridization was observed at $2,854 \mathrm{~cm}^{-1}$. X-ray powder diffraction (XRD) can be used to further analyze the structural characteristics of the C-Dots. Normally the XRD spectrum of C-Dots exhibits a large diffraction peak of $2 \theta$ values around $20-30^{\circ}$ (Thambiraj and Ravi Shankaran, 2016)-(Moradi et al., 2018; Wan et al., 2019).

\section{Optical Absorption}

Ultraviolet-Visible (UV-vis) and Photoluminesce (PL) spectroscopy known as spectroscopic techniques are widely used to investigate the linear optical absorption behavior of C-Dots. Generally, the optical absorption spectrum of C-Dots peaked around $230-340 \mathrm{~nm}$ with a tail spanning into the visible region. The UV absorption peak of $\mathrm{C}$-Dots located around $230-270 \mathrm{~nm}$ is ascribed to the $\pi-\pi^{*}$ transitions of $\mathrm{C}=\mathrm{C}$ bonds of the carbon core while the absorption at $300-340 \mathrm{~nm}$ is usually due to the $n-\pi^{*}$ transition of $\mathrm{C}=\mathrm{O}$ surface groups (Hu et al., 2017; Chan et al., 2018; Carbonaro et al., 2019).

C-Dots derived from prawn shells showed two absorption peaks at 280 and $330 \mathrm{~nm}$ due to $\pi-\pi^{*}$ and $n-\pi^{*}$ electronic transition indicating the presence of $\mathrm{C}=\mathrm{C}$ and $\mathrm{C}=\mathrm{O}$ bonds (Gedda et al., 2016). Mehta et al. also obtained similar results with two absorption peaks at 250 and $300 \mathrm{~nm}$ in C-Dots synthesized from apple juice (Mehta et al., 2015). Interestingly, these absorption transition exhibited bright blue fluorescence under UV excitation. The resultant blue emission may be connected to the zig-zag sites because of the graphene molecules found in the C-Dots (Tan et al., 2013).

Vasimalai et al. also reported two absorption bands characterized by the UV-vis spectroscopy from four types of spices (red chili, black pepper, cinnamon and turmeric). Red chili C-Dots show absorption bands at 273 and $315 \mathrm{~nm}$, black 


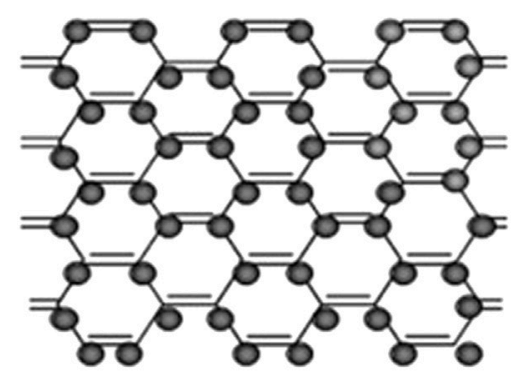

Graphene

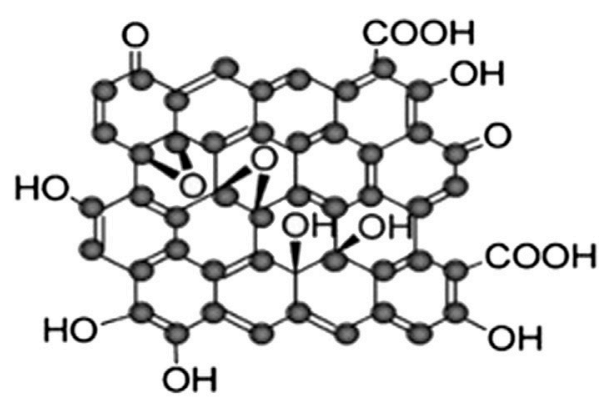

Graphene oxide

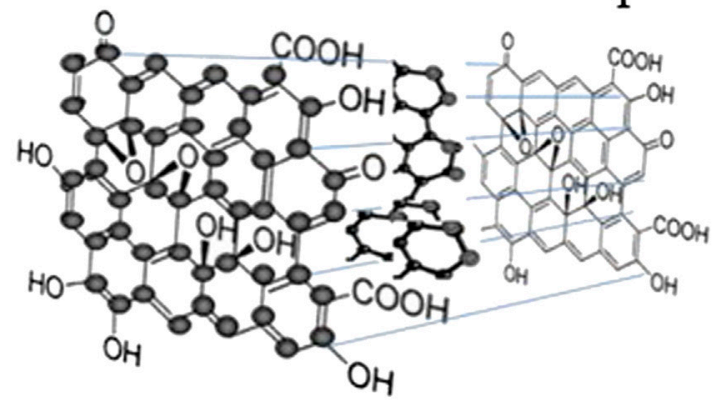

Carbon Dots

FIGURE 2 | Chemical structures of C-Dots comprise of graphene and graphene oxide structure of nanoscale carbon materials (Demchenko and Dekaliuk, 2013).

pepper C-Dots at 279 and $329 \mathrm{~nm}$, cinnamon C-Dots at 275 and $324 \mathrm{~nm}$ and turmeric C-Dots at 282 and $329 \mathrm{~nm}$. The excitation wavelength at $270-290 \mathrm{~nm}\left(\pi-\pi^{*}\right)$ and $310-400 \mathrm{~nm}\left(n-\pi^{*}\right)$ confirmed the mixture of $\mathrm{C}=\mathrm{O}$ (nonbonding oxygen states) and $\mathrm{C}=\mathrm{C}\left(\mathrm{sp}^{2}\right.$ domain) groups with brownish-yellow under visible light and blue emissions under UV light (Vasimalai et al., 2018).

Usually, C-Dots display a remarkable PL based on excitation and the fluorescent emission shows $\lambda_{\mathrm{ex}}$-dependent behavior. The capability of PL spectroscopy on estimating the PL lifetime of C-Dots has recently been proven. A clear description of the UVvis absorption and PL spectrum at specific $\lambda_{\mathrm{ex}}$ of C-Dots synthesized from Ocimum sanctum leaves can be seen in Figure 3. It should be noted that both UV-vis absorption and PL spectrums can also be used to evaluate the quantum yield (QY) of C-Dots. The QY of a sample of C-Dots was calculated in detail by a comparative approach with QY of quinine sulphate (act as reference). A simple ration of the combined PL intensity of both solutions yields the C-Dots QY (Kumar et al., 2017).

\section{Excitation Wavelength-Dependent Fluorescence, Photoluminescence and Tunability}

Most studies reported that the peak emission tends to increase the wavelength with decreasing intensity when the wavelength of the excitation increases (Figure 3A) (Arul and Sethuraman, 2018)-(Sachdev and Gopinath, 2015). It showed that the C-Dots emission is tunable by manipulating the excitation wavelength. C-Dots fluorescence emission is closely linked to the surface state of the C-Dots such as surface functional groups and degree of surface oxidation (Zhang and Yu, 2016). Different functional groups on nano C-Dots play an important role in emission wavelengths as increased content of $\mathrm{C}=\mathrm{O}$ and carboxyl groups in the C-Dots gives a higher emission efficiency (Guo et al., 2018a; Guo et al., 2018b). However, the size of the C-Dots seems does not directly relate to the C-Dots fluorescence based on the recent literature (Jiang et al., 2019). The full-color of C-Dots can be influenced by functional groups rather than the degree of surface oxidation as it had pretty much identical oxygen content. Surface oxidation primarily created surface defects that could behave as capture centers for excitation thus inducing surfacestate-related fluorescence. The exact underlying structure of the fluorescence of C-Dots is not yet fully understood and needs clarification due to the structural complexity of the C-Dots (Yao et al., 2019). Some of the researchers also stated that this unique emission property of C-Dots is caused by several factors such as carbon particles sizes, quantum confinement effect, the availability of the $\mathrm{sp}^{2}$ sites, aromatic conjugate configuration and structural defect (Liu et al., 2019; Sabet and Mahdavi, 2019). As such, fluorescent properties of C-Dots can be tuned by doping heteroatoms, surface functionalization, electrostatic attraction, and aggregation-induced emissions, researchers have put a great deal to improve the fluorescence by working on various synthesis approaches to explain different PL mechanisms.

\section{Molecular State via Electron Paramagnetic Resonance (EPR)}

Electron paramagnetic resonance (EPR) is a spectroscopic technique based on the physical properties of the electron 


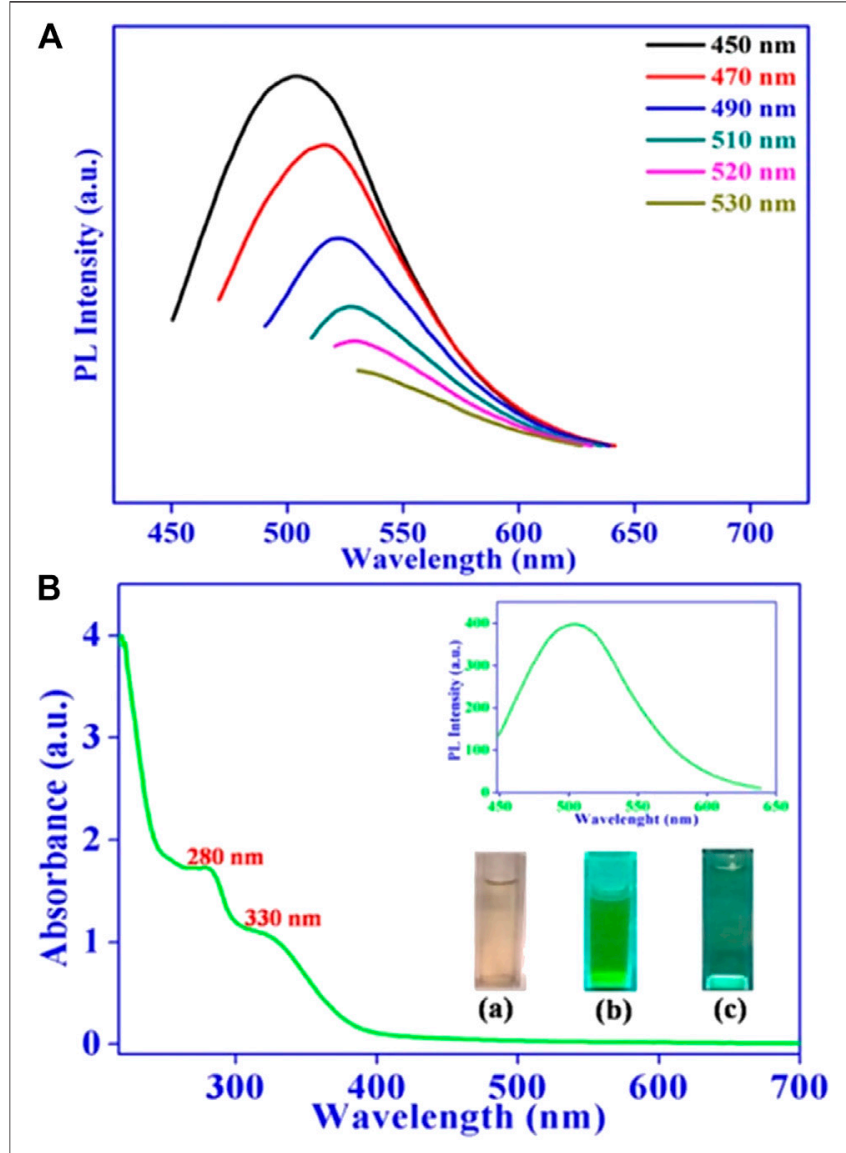

FIGURE 3 | (A) Fluorescence emission spectrum of C-Dots gained at different excitation wavelengths. (B) UV-vis absorption spectrum C-Dots synthesized from Ocimum sanctum leaves (Kumar et al., 2017).

spin. Inherently, C-Dots have several paramagnetic defect centers that can be detected using EPR (Genc et al., 2017). A large variety of information can be obtained by EPR spectroscopy, such as structural and dynamical properties of the paramagnetic species and their interaction with the surrounding environment to improve understanding of electronic coupling effects in nanocarbons (Carbonaro et al., 2019). The microscopic information obtained provide insights into the spin properties (conduction electrons, unpaired spins, dangling bonds) and the electronic states.

The $g$-values calculated from EPR data can be used for the classification of the observed dangling bond centers. The g-values of the carbon radical centers typically ranging from 2.0020 up to 2.0030 (Genc et al., 2017). Privitera et al. (2016), performed EPR studies on the C-Dots to analyze the photogenerated unpairedelectron species (paramagnetic species). The findings show a weak EPR signal at $g=2.0035 \pm 0.0005$, which reveals to long-living radicals formed by photoinduced electron transfer. The identification of a small photogeneration of radicals in the C-Dots reveals a partial double action (both electron and acceptor) of the materials (Kakazey et al., 2017). Lin et al. (2012), monitored EPR spectrum to observe the reaction of the C-Dots with the addition of oxidants such as potassium permanganate $\left(\mathrm{KMnO}_{4}\right)$ and cerium (IV). A signal at $g=1.9903$ reveals a singly occupied orbital in ground-state C-Dots which indicate an electron donor or acceptor. EPR studies have also shown a broad signal attributed from the presence of manganese (II) $\left(\mathrm{Mn}^{+2}\right)$ arising from the reaction of the C-Dots with $\mathrm{KMnO}_{4}$. $\mathrm{KMnO}_{4}$ could reduce to $\mathrm{Mn}^{2+}$ demonstrated that it can inject holes into the C-Dots. It is also found that the g-values from the EPR signal of the C-Dots reaction with cerium (IV) under $77 \mathrm{~K}$ was reduced from 1.9903 to 1.9879 after the oxidation which indicated an electron tranfer from the C-Dots to cerium (IV).

\section{SYNTHESIS ROUTES FOR C-DOTS}

In recent years, numerous synthetic approaches for the preparation of C-Dots have been explored and reported to improve the fluorescent by increasing the quantum yield and narrowing the bandgap hence producing longer wavelengths (Zhang and $\mathrm{Yu}$, 2016). These methods can be largely classified into two main routes: top-down and bottom-up methods (Figure 4) (Sagbas and Sahiner, 2019). The most selected synthesis route is focused on their superb optical properties for wide range of applications (Bhartiya et al., 2016).

\section{Overview Top-Down and Bottom-Up Method}

The top-down approach involves cutting or breaking down bulky carbon materials such as graphene oxide sheets, graphene, carbon fibers, carbon nanotubes, carbon soot graphite, etc., into nanosized particles using physical forces via laser ablation, arc discharge and electrochemical oxidation methods (Yatom et al., 2017; Reyes et al., 2016)-(Hong et al., 2016). Meanwhile, bottomup approach involves C-Dots as bulk carbon materials as selected precursor molecules transform to "quantum-sized" particles through hydrothermal, pyrolysis and microwave irradiation techniques (Kashani et al., 2019)-(Sendão et al., 2020).

The preparation of the C-Dots from biomass is more often carried out by bottom-up approach (Meng et al., 2019). This method offers great benefits as it is easy to control the surface state and the size distribution of the C-Dots to reach great quality and high yield (Saheeda et al., 2019). A simple, cost-effective and large bottom-up synthesis technique can be used under a sort of different reaction condition. In Table 1 is shown the advantages and disadvantages o of the C-Dots for "top-down" and "bottom-up" approaches.

\section{Green Synthesis of Multifunctional C-Dots}

Several researchers have recently involved in the development of C-Dots from a collection of green raw materials due to its great properties and environmental friendly synthesis routine as compared to toxic molecules in organic matter such as aromatic hydrocarbon compounds (Liu et al., 2014; Kumar et al., 2017; Bhatt et al., 2018; Liu et al., 2019; Sabet and Mahdavi, 2019; Zhao et al., 2019). Green raw materials can be obtained easily from plants or agricultural waste. The stability of the C-Dots synthesis route is therefore become important. One 


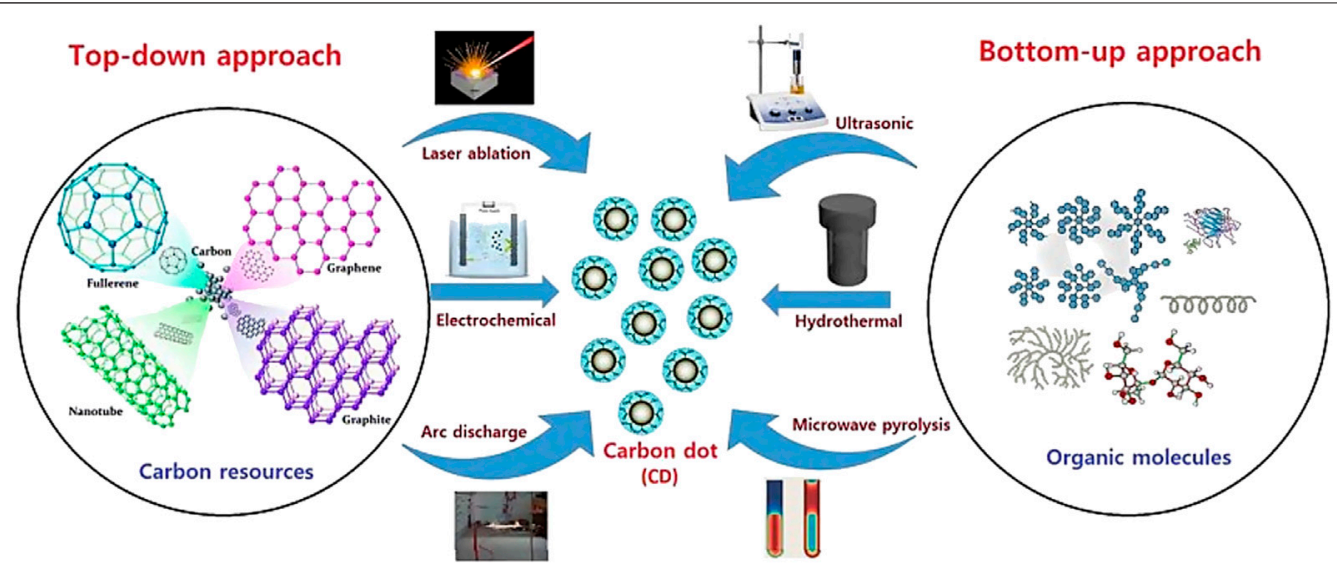

FIGURE 4 | Simple illustration for top-down and bottom-up methods (De and Karak, 2017).

way to achieve this goal is to treat raw materials systematically to ensure green carbon sources are uniform and the C-Dots are reproducible (Meng et al., 2019). Different chemical precursors such as ethylenediaminetetraacetic acid (EDTA) (Ankireddy and Kim, 2018; Yang et al., 2020), citric acid (Fang et al., 2017) and reduced glutathione (Vaz et al., 2017), and ethylene glycol (Wang et al., 2016) also have been used as the source to synthesize C-Dots. Wide applications of C-Dots in biomedical applications for instance drug delivery (D'souza et al., 2018), biosensing (Sarkar et al., 2018), bioimaging (Yang et al., 2014; Ren et al., 2018; Amjad et al., 2019) and gene transfer (Mohammadinejad et al., 2019), make it more suitable to move from chemical precursors to organic precursors. For example, numerous biomass has been used for the synthesis of C-Dots in recent years including papaya waste (Pooja et al., 2019), prawn shells (Gedda et al., 2016), grilled fish (Bi et al., 2017), Lycii Fructus (Sun et al., 2017), milk (Bajpai et al., 2019) fruit juices (Atchudan et al., 2018), etc. Nonetheless, various types of precursors may affect the properties of the resulting C-Dots due to variety composition in the samples (Liu et al., 2019). Table 2 summarises the properties of C-Dots produced from various green precursors via hydrothermal method.

\section{Hydrothermal Treatment of C-Dots}

Among all the bottom-up approaches, the hydrothermal method is the most commonly used to synthesize C-Dots from green sources as it is simple, takes less time, requires mild reaction conditions and capable of large scale synthesis ( $\mathrm{Li}$ et al., 2019). Hydrothermal method is categorized as an environmentally friendly method because of its non-polluting synthesis condition by using non-toxic materials. Different green precursor need different temperature, time and reaction conditions in hydrothermal treatment, for example, C-Dots from grass carp is prepared at $200^{\circ} \mathrm{C}$ for $20 \mathrm{~h}$ (Zhang et al. 2018) while the synthesis of C-Dots from apple juice required $150^{\circ} \mathrm{C}$ for $12 \mathrm{~h}$ (Mehta et al., 2015). Some C-Dots are doped with nitrogen, sulphur or other heteroatoms to increase the quantum yield to manipulate the intrinsic properties of the C-Dots efficiently, particularly their surface and local reactivity, optical and electronic properties (Atchudan et al., 2018). Nitrogen is commonly used as the nitrogen atoms have five valence electrons required for carbon bonding. In addition to synthetic approaches, raw materials and reaction conditions often play an important role during the development of C-Dots during carbonation and surface passivation (Radnia et al., 2020).

Generally, the raw material used for the synthesis of biomass derived C-Dots can be divided into three groups:

1) the micromolecules derived from biomass such as citric acid, glucose, sucrose, ascorbic acid etc.

2) Biomass or Plant Waste Components Such as Cellulose, Hemicellulose, Lignin and

\section{Synthesis of C-Dots}

\section{Bottom Up}

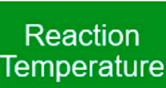

Reaction Time

\section{Solvent}

Type of

Precursor
Top Down

Post Synthesis
Size

Selection

FIGURE $\mathbf{5}$ | Main synthesis route of C-Dots and the key factors affecting the design of C-Dots. 
A
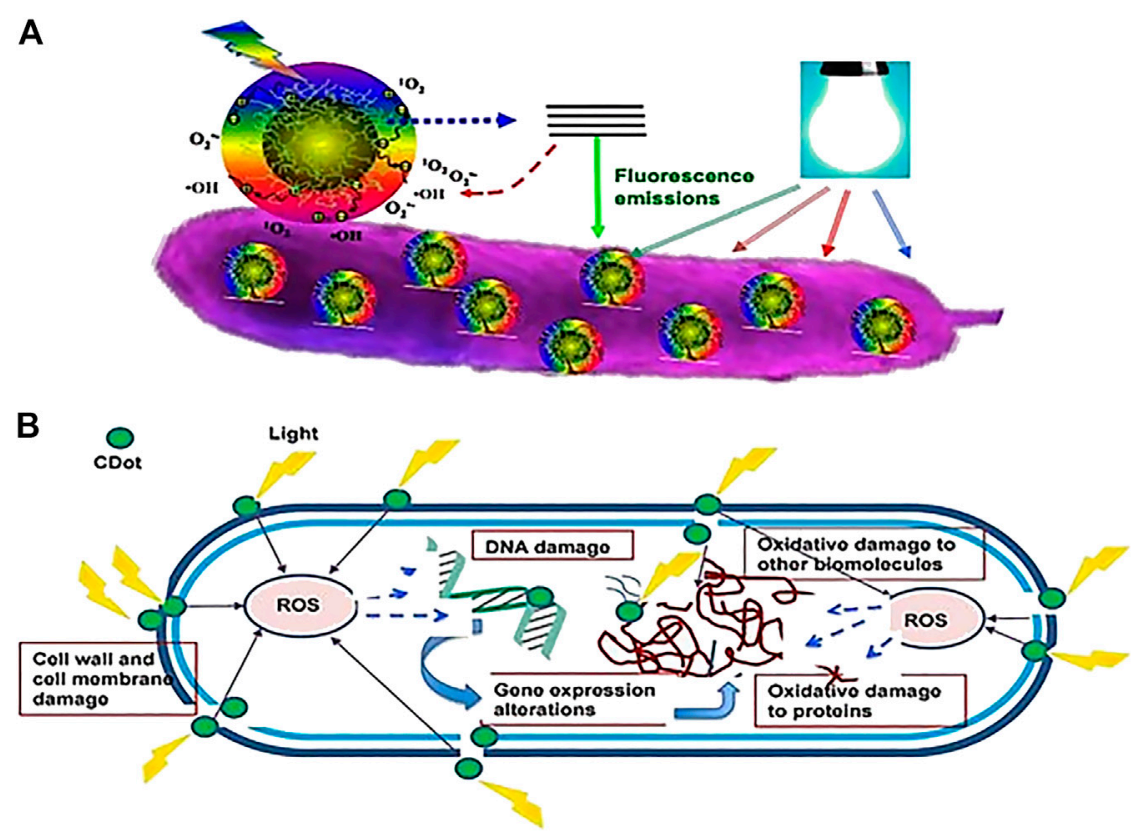

FIGURE 6 | Cartoon diagram on the mechanism of action for photoactivated antibacterial activity of C-Dots (A) Adhesion of C-Dots to the bacterial surface and visible-light-induced ROS generation (B) Intracellular ROS causes damage to the bacterial cell (Dong et al., 2020).

TABLE 1 | Different "top-down" and "bottom-up" approaches in synthesizing C-Dots.

Bottom-up Hydrothermal

\begin{tabular}{|c|c|c|}
\hline Approaches & Synthesis method & Advantages \\
\hline \multirow[t]{4}{*}{ Top-down } & Laser ablation & Simplicity \\
\hline & & $\begin{array}{l}\text { The size of the C-Dots can be controlled by } \\
\text { altering the input laser pulses }\end{array}$ \\
\hline & Arc discharge & $\begin{array}{l}\text { C-dots are produced from the purification of } \\
\text { carbon nanotubes as the by-product }\end{array}$ \\
\hline & $\begin{array}{l}\text { Electrochemical } \\
\text { oxidation }\end{array}$ & $\begin{array}{l}\text { Easy to manipulate the dimension of the C-Dots } \\
\text { by controlling applied potential } \\
\text { Simple setup experimental }\end{array}$ \\
\hline
\end{tabular}

Raw materials can be from natural resources or biomass

Inexpensive apparatus setup

Parameters of the experiment can be controlled

Able to large scale synthesis

Disadvantages

Low quantum yield ranging from 4.5 to $18 \%$

Have impurities like amorphous carbon, graphitic

carbons and metal catalyst

Complex composition

Low quantum yield ranging from 2.3 to $8.7 \%$

Required longer time up to $12 \mathrm{~h}$

Further modification is necessary such as the types of the redox electrodes

Contain impurities like larger and undissolved particles

Wide size of the C-dots from 37 to $66 \mathrm{~nm}$

Quick synthesis reaction

Microwave irradiation Rapid and constant volumetric heating
Easy operation

Pyrolysis
Small volumes of microwave reactors restricting
Required high temperature from 200 up to $450{ }^{\circ} \mathrm{C}$ their use in large scale reactions

Purification and separation are difficult

\section{Ref}

Don et al. (2018) Shahidi et al. (2018)

Yu et al. (2016)

Arora and Sharma (2014)

Xu et al. (2004)

An et al. (2014)

Dey et al. (2014)

Javan et al. (2019)

Tang et al. (2014)

Bao et al. (2011)

Liu et al. (2016)

Raveendran et al. (2019)

Khan et al. (2019)

Diao et al. (2018)

Bhatt et al. (2018)

Sarkar et al. (2016)

Su et al. (2019)

Dager et al. (2019)

Murugan and

Sundramoorthy (2018)

Thakur et al. (2019)

Tan et al. (2014)

Lu et al. (2015)

Singh et al. (2019)

Zhao et al. (2019)

Pierrat et al. (2015)

De Medeiros et al., (2019) 
TABLE 2 | Summary of the properties and applications of C-Dots prepared by using various green precursors via hydrothermal approach.

\begin{tabular}{|c|c|c|c|c|c|c|c|}
\hline Carbon source & $\begin{array}{l}\text { Particle } \\
\text { size }(\mathrm{nm})\end{array}$ & $\begin{array}{c}\text { Temp } \\
\text { ('C) }\end{array}$ & $\begin{array}{c}\text { Time } \\
\text { (hr) }\end{array}$ & $\begin{array}{l}\text { Quantum } \\
\text { yield (\%) }\end{array}$ & Fluorescence & Application & Ref \\
\hline Lemon juice & $4-5$ & 240 & 12 & 21 & Green & Detection of $\mathrm{V}^{5+}$ ions & Hoan et al. (2019) \\
\hline $\begin{array}{l}\text { Catharanthus roseus } \\
\text { leaves }\end{array}$ & 5 & 200 & 4 & 28.2 & Greenish blue & $\begin{array}{l}\text { Multi-ion detection } \\
\text { Bioimaging }\end{array}$ & Arumugham et al. (2020) \\
\hline Betel leaf ${ }^{\mathrm{a}}$ & $3-6$ & 200 & 12 & 12 & Blue & Detection of $\mathrm{Fe}^{3+}$ & Atchudan et al. (2019) \\
\hline Pear juice & $2.0 \pm 1.0$ & 180 & 6 & 10.8 & Blue & Detection of $\mathrm{Al}^{3+}$ & Bhamore et al. (2018) \\
\hline Coriander leaf & $1.5-2.98$ & 240 & 4 & 6.48 & Green & $\begin{array}{l}\text { Biomaging } \\
\text { Detection of } \mathrm{Fe}^{3+}\end{array}$ & $\begin{array}{l}\text { Sachdev and Gopinath } \\
\text { (2015) }\end{array}$ \\
\hline Wheat straw & $<2$ & 250 & 10 & 9.2 & Blue & $\begin{array}{l}\text { Detection of } \mathrm{Fe}^{3+} \\
\text { Bioimaging }\end{array}$ & Yuan et al. (2015) \\
\hline Pea sesame & $\begin{array}{l}3.1-4.3 \\
1.7-2.8\end{array}$ & 180 & 6 & $\begin{array}{l}2.54 \\
3.37\end{array}$ & Blue & Labeling pathogenic fungi & Su et al. (2020) \\
\hline Water hyacinth leaves & 5.22 & 160 & 24 & 17.02 & Green & Sensor for pretilachlor & Deka et al. (2019) \\
\hline Prunus mume fruit ${ }^{a}$ & $7-11$ & 180 & 5 & 16 & Blue, green & $\begin{array}{l}\text { Cell imaging } \\
\text { Biomedical }\end{array}$ & Atchudan et al. (2016) \\
\hline Ginkgo leaf & $1-4$ & 180 & 12 & 21.7 & Blue & Bioimaging & Li et al. (2017) \\
\hline Dragon fruit ${ }^{\mathrm{a}}$ & 2.5 & 180 & 12 & & Blue & Bioimaging & Arul et al. (2017) \\
\hline $\begin{array}{l}\text { Abelmoschus manihot } \\
\text { flower }\end{array}$ & 9 & 220 & 4 & 30.8 & Blue & Bioimaging & Wan et al. (2019) \\
\hline Kiwi fruit $^{\mathrm{a}}$ & 3.59 & 180 & 12 & & Blue & Photocatalyst & $\begin{array}{l}\text { Arul and Sethuraman } \\
\text { (2018) }\end{array}$ \\
\hline Phyllanthus acidus & $3-5$ & 200 & 20 & & Blue & Detection of $\mathrm{Fe}^{3+}$ & Atchudan et al. (2018) \\
\hline Tulsi leaves & 5 & 200 & 4 & 3.06 & Bluish & $\begin{array}{l}\text { Bioimaging } \\
\text { Patterning agents }\end{array}$ & Bhatt et al. (2018) \\
\hline Prawn shells & 4 & 200 & 8 & 9 & Blue & Detection of $\mathrm{Cu}^{2+}$ & Gedda et al. (2016) \\
\hline Rose-heart radish ${ }^{a}$ & $1.2-6$ & 180 & 3 & 13.6 & Blue & $\begin{array}{l}\text { Detection of } \mathrm{Fe}^{3+} \\
\text { Bioimaging }\end{array}$ & Liu et al. (2017) \\
\hline Lycii fructus & $2-5$ & 200 & 5 & 17.2 & Blue & $\begin{array}{l}\text { Detection of } \mathrm{Fe}^{3+} \\
\text { Cell imaging }\end{array}$ & Sun et al. (2017) \\
\hline Neem leaves $^{a}$ & 3.2 & 150 & 4 & 27.2 & Blue & $\begin{array}{l}\text { Detection of } \mathrm{H}_{2} \mathrm{O}_{2} \text { and } \\
\text { ascorbic acid }\end{array}$ & Yadav et al. (2019) \\
\hline Sweet potato & $2.5-5.5$ & 180 & 18 & 8.62 & $\begin{array}{l}\text { Blue, green } \\
\text { and red }\end{array}$ & $\begin{array}{l}\text { Detection of } \mathrm{Fe}^{3+} \\
\text { Cell imaging }\end{array}$ & Shen et al. (2017) \\
\hline
\end{tabular}

${ }^{a}$ Nitrogen doped C-Dot.

3) natural biomass such as peanut shell, rice husk, straw, etc.

By using different groups of biomass, various structures and optical properties of C-Dots could be produced as carbon atom numbers, carbon chain length, surface functional groups could have an impact on the formation process. The formation of C-Dots is divided into different steps: dehydration, polymerization, aromatization, carbonization and passivation. During the hydrothermal reaction in the presence of sucrose, sucrose is hydrolyzed to form fructose and glucose. For the synthesis of C-Dots from biomass components (e.g., cellulose, hemicellulose, chitin, lignin) or natural biomass, it has been reported the disruption of cellulose in the hydrothermal process is performed at a relatively high temperature (higher than $200^{\circ} \mathrm{C}$ ). The physical structure of cellulose is initially disintegrated by hydrolysis where the long chain cellulose breaks down to oligomers compounds composed of $\mathrm{C} / \mathrm{H} / \mathrm{O}$ elements and then further to glucose (Su et al., 2019). These small compounds then follow isomerization, dehydration and decomposition steps producing soluble intermediates such as furfurals, organic acids, ketones and aldehydes (Sevilla and Fuertes, 2009), (Wang et al., 2018). Subsequently, hydronium ion formed from these acids act as a catalyst where these intermediaries undergo dehydration, polymerization, condensation and transform into soluble polymeric product. Then, aromatization reactions and creation of aromatic clusters occur via aldol condensation (Chen and Tseng, 2017) and cycloaddition reactions (De and Karak, 2013). A single burst nucleation formed when the concentration of these aromatic clusters reach a critical supersaturation point, and C-Dots are formed. On the other hand, residual precursors such as hydrophilic and oxygen-containing fragments present in the solution tend to stay around the surface of the cluster to form the surface passive layer forming C-Dots with a hydrophobic core and a functional groups rich hydrophilic shell (Sevilla and Fuertes, 2009), (Sahu et al., 2012).

\section{DESIGN PARAMETERS AND FACTORS AFFECTING TUNABLE BANDGAP OF THE C-DOTS}

The diversity of C-Dots is primarily attributed by the variety of carbon precursors and synthetic strategies. In C-Dots synthesis, the PL behaviour and quantum yield are the two crucial concerns in which they can be theoretically controlled by the particle size 
and surface states. The process conditions affecting the chemical structure, crystallinity and size of C-Dots are the molecular structure of the precursors, reaction time, reaction temperature and solvent as shown in Figure 5. The selected reaction conditions are critical because of their strong influence on precursor reactivity, separation of the nucleation and growing stages of the prepared C-Dots.

\section{Particle Size}

The emission wavelength is well known to depend on the particle size of the C-Dots which may affect the conjugated domain in the C-Dots cores. Bandgap tuning is often related to the size of the graphite core (Gao et al., 2018). C-Dots commonly have a particle size of less than $10 \mathrm{~nm}$ with nearly spherical shapes. The overall size of the C-Dots with conjugated graphic core possesses photoluminescence-dependent size property. Photoluminescence of C-Dots emerges from conjugated graphitic core due to exciton containment (Barman and Patra, 2018). The composition of the distinctive C-Dots consists of $\mathrm{sp}^{2}$ hybridized carbon composition and amorphous carbon framework enclosed with abundant functional groupings or species (Gao et al., 2018).

Zhu et al. (2019) conducted a seeded growth method to yield C-Dots by adjusting the seed amount $(0.5,1,2$, or $3 \mathrm{mg})$ and reaction time $(6-10 \mathrm{~h})$. The experiment showed that the C-Dots emitted colour-tunable fluorescence (blue, green, yellow and orange emissions) which linked to the $\pi$-conjugated domains within C-Dots core as the size of the C-Dots increased. The samples are synthesized using dimethylformamide (DMF) as the solvent with citric acid and urea via solvothermal reaction. Six different C-Dots with average sizes of $1.6 \pm 0.2,3.6 \pm 0.3,4.6 \pm 0.2$, $5.0 \pm 0.2,5.4 \pm 0.2$ and $5.6 \pm 0.2 \mathrm{~nm}$ were synthesized. The quantum yields were found to be $17,17,24,24,26$ and $26 \%$ respectively. The amount of nitrogen $(N)$ slowly increased when the diameter of the particle size is increasing with the presence of urea as the precursor through their synthesis reaction time. The increasing amount of nitrogen may also contributed to the C-Dots colour emission.

To understand more about the quantum confinement effect, Sarkar et al. (2016), carried out the synthesis of different size water soluble C-Dots from sucrose through a simple lowtemperature hydrothermal method. Four different samples denoted as S1, S2, S3, and S4 were prepared at a different time $(120$ and $150 \mathrm{~min})$ and temperature $\left(120\right.$ and $\left.150^{\circ} \mathrm{C}\right)$ with the same initial concentration of sucrose $(1.5625 \mathrm{~g})$. Their results showed that particulate size increased with the temperature (ranging from 5 to $10 \mathrm{~nm}$ ). S1 and S2 were synthesized at different times (120 and $150 \mathrm{~min}$ ) at the same temperature $\left(120^{\circ} \mathrm{C}\right)$. S1 shows emission colour from light purple, purple, purple-blue, blue, and deep blue to light green when excited at $240-440 \mathrm{~nm}$ with a maximum intensity of $280 \mathrm{~nm}$. This may due to the presence of $\mathrm{sp}^{2}$ clusters and various attachments (C-H, Si-O-Si, Si-H, and C-O-C) which reduced energy gap and different energy trap states and different polyaromatic fluorophores with the skeleton of carbon (Sarkar et al., 2016). For S2 it was observed that red emission peak shifted with excitation from 320 to $440 \mathrm{~nm}$ with a maximum intensity of
$360 \mathrm{~nm}$. For S3 and S4, the sample was synthesized at the same synthesis time (150 $\mathrm{min}$ ) but at different temperatures (150 and $180^{\circ} \mathrm{C}$ ). It was observed that the sample S3 showed a monotonic redshift when the $\lambda$ ex was increasing from 431.88 to $551.31 \mathrm{~nm}$ with maximum intensity at $360 \mathrm{~nm}$ which was similar with sample S2. Sample S4 had a wide range of excitation wavelength from 320 to $520 \mathrm{~nm}$ with a maximum intensity of $360 \mathrm{~nm}$ like S2 and S3. It should be noted that C-Dots may have different skeleton chromophoric centers and different energy trap centers when the particle size of C-Dots increased. Subsequently, it may give effect to the $\pi$-conjugated graphitic core in the C-Dots as it showed size-dependent luminescent properties as the size is the main factor for photoluminescence properties.

Considering the theoretical and experimental research, $\mathrm{Ye}$ et al. worked on two different ways to synthesis C-Dots from anthracite coal. First approach was by chemical oxidative treatment where the reaction temperature was directly controlled the final size of the C-Dots while another approach was via separation by cross-flow ultrafiltration to distinguish them by the size of the C-Dots (Ye et al., 2015). The average sizes of four different C-Dots were $4.5 \pm 1.2,16 \pm 3.3,41 \pm 6.4$, and $70 \pm 1.5 \mathrm{~nm}$ by cross-flow ultrafiltration. As the size of the C-Dots increases, the bandgap decreased from $\sim 2.4 \mathrm{eV}$ (green) to $\sim 1.9 \mathrm{eV}$ (orange-red) and red-shifted from $\sim 520$ to $\sim 620 \mathrm{~nm}$. This occurrence was related to the quantum confinement effect graphitic conjugated core. This phenomenon occurred when the particles are smaller than excitons known as Bohr exciton radius at which the carriers of the charge are spatially confined within the particles (Sumanth Kumar et al., 2018). The quantum yield was found to decrease from 1.1 to $0.38 \%$ because of the size of the C-Dots increase (from 4.4 to $70 \mathrm{~nm}$ ). This phenomenon was caused by the defects in the C-Dots since larger C-Dots had fewer defect sites per unit area thus less emissive. As the size of the C-Dots increased, the content of functional groups (carbonyl groups) became smaller. The functional groups were similar to the defects states and $\mathrm{sp}^{3}$ carbon as they also induced structural deformation to the aromatic core and gave effect to the overall emission (Wang et al., 2016). It was also found that temperature played an important role in regulating C-Dots diameters (Barman and Patra, 2018). Higher temperatures result in more oxidation and make C-Dots smaller, therefore, enlarged the bandgap of the C-Dots (Ye et al., 2015). The functional groups on the C-Dots changed with the synthesis temperature. Higher synthesis temperatures $\left(130-150^{\circ} \mathrm{C}\right)$ increased $\mathrm{COOH}$ content and decreased the $\mathrm{C}-\mathrm{C}$ content which also effected the tunable bandgap of the C-Dots due to size effect and functionality effect (Kumar et al., 2014). In conclusion, larger particle-sized of C-Dots primarily isolated conjugated $\pi$-domains are highly probable to regulate the emission and leads to a variation in the energy bandgap.

\section{Effect of Temperature}

Temperature is a crucial factor in the design of C-Dots as the synthesis method required carbonization of biomass wastes as carbon source. Some researchers (Xiong et al., 2017)-(Dong et al., 2012; Ogi et al., 2016; Zhou et al., 2017) have studied the morphologies and the structural characterizations of citric acid 
based C-Dots at various reaction temperatures. Generally, the C-Dots consists of a carbon graphitic core and an amorphous carbon region. An increase in the temperature give rise to the growth of the core and a simultaneous reduction of the amorphous region affecting the optical properties. This is due to the fact that the high reaction temperatures tend to fully carbonize the functional groups of the amorphous surface, resulting in a larger size of the carbon core which leads to a shift of photoluminescence towards larger wavelengths. Zhu et al. (2013) found that as the reaction progressed from low temperature to high temperature, the polymer-like C-Dots were changed into carbogenic C-Dots. The surface/molecule state plays the leading role in the polymer-like C-Dots, while the synergistic effect of the carbon core and the surface/molecule state contributed to the PL of carbogenic C-Dots. However, the carbonization of surface groups generally leads to decrease in quantum yield. Therefore, the maximum quantum yield is attained at the in-between temperature range where both the core and shell structures coexist. According to most of the published literature, the quantum yield for prepared C-Dots can usually reach a maximum when the reaction temperature is in the range of $150-200^{\circ} \mathrm{C}$, regardless of the different synthesis method such as hydrothermal, thermal decomposition, pyrolysis, microwave irradiation. Wu et al. (2015) synthesized water-soluble carbon nanodots (CNDt) via onepot simple hydrothermal carbonization of lignocellulose-larch by changing the reaction temperature from 200 to $260^{\circ} \mathrm{C}$. Increasing the reaction temperature decreased the average size and increased the fluorescence quantum yield of the CNDt with an obvious blue shift of the excitation and emission peaks was also observed. Zhang et al. (2016) investigated the effect of reaction temperature (from 120 to $220^{\circ} \mathrm{C}$ ) and nitrogen doping on the structure and fluorescence properties of $\mathrm{C}$-Dots by using citric acid as carbon source and ammonia solution as nitrogen source. Their findings showed that reaction temperature has obvious effect on carbonization degree, quantum yield, ultraviolet-visible (UV-vis) absorption and photoluminescence (PL) spectra but less effect on functional groups, nitrogen doping degree and fluorescence lifetime of nitrogen doped CDs.

\section{Reaction Time}

The effect of reaction time on the optical properties of C-Dots is closely related to reaction temperature. Similarly, the longer reaction time result in higher carbonization degree, which promotes the growth of the carbon core and thus affects the optical properties of the related C-Dots. For example, He et al. (2017) conducted a systematic study on the correlation between the reaction temperature, time and different types of C-Dots formations through microwave-assisted synthesis. By using acetylacetone and ammonia as initial reactants, they successfully developed typical C-Dots with stable optical properties where their most photoluminescence arises from the carbon cores through prolonging the reaction time. It is worthy to note that only when the carbonization process is performed under a suitable temperature, then the optimization of reaction time is significant in tuning the optical properties of
C-Dots (Hu et al., 2014). The successful synthesis of impactful C-Dots could not be accomplished by adopting an ultra-long reaction time with no prior high enough reaction temperature. For example, Bandi et al. (2016) observed that reaction time had a significant impact on the fluorescence quantum yield of C-Dots synthesized from onion waste by a simple hydrothermal approach. The quantum yield of C-Dots first increased with the increase of reaction time and reaches a maximum and then decreased along with further prolonging of reaction time. Papaioannou et al. (2019) also reported the synthesis of C-Dots from glucose with varying reaction time from 2 to $12 \mathrm{~h}$ using hydrothermal method. They found a decrease in particle size, while a higher level of mono dispersity and less crystalline phase over reaction time.

\section{Surface-Related Defective Sites}

The surface state of the C-Dots such as chemical compositions and surface functional groups are closely related to the multicolour emissions from C-Dots (Barman and Patra, 2018). It is well accepted that photoluminescence (PL) of the C-Dots are considered originating from the surface state. Surface states are oxygen $(\mathrm{O})$, sulphur $(\mathrm{S})$ or nitrogen $(\mathrm{N})$ that are containing functional groups. Different surface states mean different energy levels, resulting in various electronic transition possibilities and different PL properties. C-Dots predominantly consist of graphitic $\mathrm{sp}^{2}$-core (aromatic domain) bounded by an $\mathrm{sp}^{3}$ matrix with numerous surface functionalities such as $\mathrm{C}-\mathrm{O}$, $\mathrm{C}=\mathrm{O}, \mathrm{C}-\mathrm{O}-\mathrm{C}, \mathrm{O}=\mathrm{C}-\mathrm{OH}$ and others (Yi et al., 2019). Surface defects can act as trapping centers for excitons and abundant groups such as amino and carboxyl groups on the C-Dots surface tend to form a conjugated $\pi$-domain structure, causing surface state-related emissions which resulted from the higher degree of oxidation and surface function (Zhu et al., 2019). Cao, An and Han worked on a series of C-Dots with different concentrations through the hydrothermal process from citric acid as a carbon source and ethylene imine polymer (PEI) as nitrogen source (Cao et al., 2020). The characterization of the C-Dots showed the surface of the C-dots filled with functional groups (hydrophilic oxygen and nitrogen). Increasing concentration of C-Dots resulted in more oxygen-related groups, impose complex surface states to traps excitons under excitations which bring tunable fluorescence, therefore, generating new energy level (Khan et al., 2015). The increase of C-Dots concentration (from 0.12 to $2.47 \mathrm{~g} / \mathrm{L}$ ) resulted redshift fluorescence (from 444 to $478 \mathrm{~nm}$ ) from the experiment. It was observed that this factor lead to the increase of the C-Dots PL lifetime from the surface defects states as higher concentration draws complex surface state to the C-Dots structure which was caused by more oxygen-related groups (Hu et al., 2015; Jeong et al., 2016).

Choi et al. prepared nano-sized C-Dots via oxidation and hydrothermal reaction followed by the introduction of an electron-accepting functional group of nitro $\left(-\mathrm{NO}_{2}\right)$ and nitrile (-CN) to the C-Dots to control the band-gap energy and frontier molecular orbital energy levels (Choi et al., 2018). The functionalized process was reported not affecting the particle size of the C-Dots because the diameter of the C-Dots can be easily manipulated by the reaction time and pore size of the filters. 
The band gap of the nano-sized C-Dots has been successfully tuned by functionalization with electron-accepting groups. The band gap for pure C-Dots without any modification on the structure was $\sim 1.12 \mathrm{eV}$ but it decreased to $\sim 1.05 \mathrm{eV}$ for nitrofunctionalized C-Dots and the emission was found to be redshifted at $480 \mathrm{~nm}$. The nitrile-substitution to the C-Dots also resulted in a smaller bandgap of $\sim 1.03 \mathrm{eV}$ with even more redshifted green emission at peak $494 \mathrm{~nm}$. In comparisaon to nitro groups, the nitrile groups showed a greater narrowing effect of the bandgap. From this study, the degree of the bandgap can be tuned by carefully choosing the functional species and the degree of functionalization. Functionalization shifted the spectral bands of absorption and photoluminescence to longer wavelength which defined the relationship between functionalization groups and the C-Dots bandgap energy.

The technique which improved the degree of surface oxidation leading to multicolour emissions with a smaller bandgap that has been thoroughly investigated (Zhu et al., 2015). Ding et al., reported that the C-Dots red-shifted PL related closely to their degree of surface oxidation using urea and $p$-phenylenediamine via hydrothermal approach (Ding et al., 2016). C-Dots possess excitation-independent fluorescence from blue to red after column chromatography with a quantum yield of approximately $24 \%$ of red-emitting C-dots. An increase in the degree of surface oxidation reduces the bandgap of the C-Dots as the number of the oxygen atoms invading the structure eventually determined the tunable PL. To sum up, high degree surface oxidation always has a large surface defects sites on the C-Dots, leading to narrower energy band gap and thus emission regulation.

Surface passivation is one of the methods of surface functionalization developed to improve the optical properties of C-Dots. Surface passivation with organic molecules and diamine compounds were used for the passivation of C-Dots to provide stable surface energy traps in the C-Dots ( $\mathrm{Li}$ et al., 2012; Park et al., 2016). Polyethylene glycol (PEG) is the common precursor used as a passivating agent because of its abundance of carboxyl groups (Fan et al., 2014). For example, the major beneficial effect of C-Dots surface passivation was studied by Zhang et al. (2016) to tune the bandgap of the C-Dots. They extracted C-Dots by introducing a thin passivating layer on the C-Dots surface using polyethylene glycol $\left(\mathrm{PEG}_{400}\right)$ non-conjugated polymer with a molecular weight of $400 \mathrm{~g} / \mathrm{mol}$ and exhibited blue fluorescent C-Dots. In a standard reaction, the $\mathrm{PEG}_{400}$ was then mixed with $\mathrm{PEG}_{1000}$ (with a molecular weight of $1,000 \mathrm{~g} / \mathrm{mol}$ ) which tuned the emission colour to green. Lastly, further surface passivation was done by using EDA (Ethylene-dioxyethylamine) as a passivation reagent (Zhang et al., 2016). The emission colour of the fluorescent C-Dots was turned from green to orange. The prepared C-Dots had different emission colours like blue, green and orange consists of $\mathrm{C}$ (carbon), $\mathrm{H}$ (hydrogen) and $\mathrm{O}$ (oxygen) components with additional $\mathrm{N}$ (nitrogen) component after added EDA into reaction. C-N bonds were assumed to be capable of modifying the electronic structures of the C-Dots which created low energy band gaps in the C-Dots, hence tuning their emissions.

\section{Heteroatom Doping}

Doping is another technique to change the nanomaterial's internal properties which are closely linked to the HOMOLUMO energy gaps that can be tuned with adjusted amounts and certain types of dopants (Park et al., 2016). Doping also can enhance the quantum yield of the C-Dots. The chosen doping elements can be generally classified as heteroatoms (nonmetal and metal atoms). Different dopants such as N, S, and P have been widely used to evaluate the C-Dots characteristic features towards applications (Barman and Patra, 2018). Tailoring the structural defects, surface functional groups and interactions among carbon atoms with their neighboring atoms may introduce new surface properties of the C-Dots that is closely related to heteroatom doping with other elements. Additionally, there are two types of doping in terms of the number of dopants, namely single doping and multi-doping (Favaro et al., 2015; Yi et al., 2019).

Nitrogen doping is the most adaptable dopant atoms in C-Dots as it has the comparable atomic size to carbon atoms, unique electron configurations and high electronegativity (Zhu et al., 2019). Nitrogen (N) atom could inject electrons into the C-Dots after successful doping thereby modifying the internal electronic structure. Thus $\mathrm{N}$ atom can easily be integrated into the skeleton of carbon material. The wavelength of the red-shifted emissions has resulted from the nitrogen atom which produces a new surface state energy level. Jiang et al., have synthesized three different types of phenylenediamines isomers (o-PD, mPD and pPD) C-Dots denoted as p-C-Dots, o-C-Dots and m-C-Dots through purification using silica gel column chromatography and the emission of the C-Dots were observed in solution and polymer films (Jiang et al., 2015). All these three types of C-Dots emits three primary emission colors which are red (p-C-Dots), green (o-C-Dots) and blue (m-C-Dots) via a solvothermal method. By carefully analyzing the data for the characterization of the C-Dots, it was found that percentage of the nitrogen content for each C-Dots is 3.69\% (m-C-Dots), $7.32 \%$ (o-C-Dots) and $15.57 \%$ (p-C-Dots). Hence, it can be concluded that differences of nitrogen content in the C-Dots might be attributed to the different PL characteristics of the C-Dots.

Nitrogen doping will have a great impact on tunable PL of the C-Dots. From a simple hydrothermal method, Atchudan et al., have produced hydrophilic nitrogen doped-based from the dwarf banana peel (bio-waste) (Atchudan et al., 2020). Red shifted excitation wavelength was from 310 to $460 \mathrm{~nm}$. The peaks of excitation and emission shifted to long-wavelength because the surface of the C-Dots consisted of oxygen-containing and nitrogen-containing groups in the hydrophilic C-Dots which introduced trap states with different energy levels. The introduction of the nitrogen groups by doping also increased the quantum yield of the C-Dots by 23\% (Atchudan et al., 2020). Hydrophilic nitrogen in the C-Dots could be an ideal candidate or alternate for fluorescent nanoprobe for detection of metal ions, as a fluorescent ink or as a substitute for commercial dyes (Bandi et al., 2018; Ma et al., 2019). 
Zhang et al., reported tunable PL (from blue to yellow) through altering the ratio of the nitrogen $(\mathrm{N})$ and sodium $(\mathrm{Na})$ by $\mathrm{Na}$ ion dispersion (NID) technique to prepare C-Dots doped with nitrogen that are solely solid (Zhang et al., 2020). The quantum yield of the N-doped C-Dots had increased greatly to $80.7 \%$ as the nitrogen concentration increased with the urea ratio increasing from 0.5 up to $3.5 \mathrm{~g}$ of urea. Introduction $\mathrm{N}$-doping generated different trap states as amino $\mathrm{N}$ and $\mathrm{Na}$ ion of surface state could generated surface defects. Hence, the emission of fluorescence could be tuned and tunable multicolour photoluminescence could be realized from blue to yellow.

Phosphorus $(\mathrm{P})$ atoms, compared to nitrogen $(\mathrm{N})$, are larger than carbon atoms. Phosphorus was shown to be capable of creating substitution defects in carbon clusters consisting of mostly $\mathrm{sp}^{3}$ bonds and acted as the $\mathrm{n}$-type donor. Hence, $\mathrm{P}$ atoms can alter the electronic and optical properties of C-Dots (Zhou et al., 2014). Doping of phosphorus into the nitrogen-doped polymeric C-Dots was carried out by Zhi et al. using citric acid or malic acid as the carbon precursor together with ethylenediamine as the nitrogen precursor (Zhi et al., 2018). The effect from the phosphorus doping gives the fluorescence lifetime citric acid polymeric C-Dots to decrease while it did not effect the malic acid polymeric C-Dots. The malic acid C-Dots had a lower quantum yield than the C-Dots derived from the citric acid after doping it with different levels of phosphorus due to multiple pathways for relaxation. The doping agent was not toxic to the bacteria and plays a good eco-friendly fluorescent materials (Zhou et al., 2014).

Sulphur-doped C-Dots has recently received a great deal of publicity, as sulphur atoms can also provide a new level of energy or to control the initial bandgap of C-Dots (Naik et al., 2018). Gao et al. have synthesized multiple colour emissive C-Dots from green, yellow to red by doping sulphur (S) elements and water in a solvothermal method (Gao et al., 2020) by using o-phenylenediamine and $\mathrm{N}$-dimethylformamide (DMF) as the carbon precursor. Thiourea was added as the $S$ doping to the C-Dots. The three colour emission originated from the transition of absorption bands in the lower energy region. The green emission $(2.36 \mathrm{eV})$ came from the pyridinic $\mathrm{N}$ while yellow fluorescent $(2.15 \mathrm{eV})$ came from an increased amount of graphitic $\mathrm{N}$ and becomes prominent after $\mathrm{S}$ doping which influences in narrowing the bandgap. The redshift fluorescence $(1.98 \mathrm{eV})$ was due to an increasing degree of surface oxidation and generates a carboxyl group hence narrow bandgap. The quantum yield for the green, yellow and red C-Dots is 22, 26 and $20 \%$. Conclusively, S doping increases the graphitic nitrogen content significantly and produce colour emissions from green to yellow, while adding water to the C-Dots produces carboxylic surface group which influences the C-Dots emission from yellow to red. Table 3 shown a summary of doped C-Dots.

\section{Effect of Solvent}

It is worth noting that the solvent is also another critical parameter to control the C-Dots' properties andcharacteristics (Zhu et al., 2019) as the solvents can regulate the dehydration and carbonization of precursors. The bandgap of the C-Dots can be easily tunable through varying the concentration of the solvents (Zhan et al., 2018). The C-Dots can be produced under mild solvothermal conditions using 1,3,6-trinitropyrene (TNP) in two types of main organic pure solvent (DMF and EtOH) to narrow the band gaps and two types of auxiliary solvent (acetic acid and water) to decrease the lateral size for blue-green emissions. From the characterization studies, the fluorescent C-Dots emitted colourful emission such as blue $(2.82 \mathrm{eV})$, green $(2.59 \mathrm{eV})$, yellow $(2.28 \mathrm{eV})$ and red $(2.14 \mathrm{eV})$ light under different concentration of the solvent of $\mathrm{DMF} / \mathrm{H}_{2} \mathrm{O}(2: 1 \mathrm{vol} / \mathrm{vol}), \mathrm{EtOH} /$ $\mathrm{CH}_{3} \mathrm{COOH}$ (450:1 vol/vol), pure EtOH and pure DMF with increasing yield (50, 70, 87 and 90\%). Pure DMF and EtOH solvent emitted red and yellow emissions while the mixture of $\mathrm{DMF} / \mathrm{H}_{2} \mathrm{O}$ (2:1 $\left.\mathrm{vol} / \mathrm{vol}\right), \mathrm{EtOH} / \mathrm{CH} 3 \mathrm{COOH}$ (450:1 $\left.\mathrm{vol} / \mathrm{vol}\right)$ exhibited blue and green emissions. Different type of solvents give different polarity with different concentration exhibits multicolour band gap fluorescence.

Some research groups have found that differentiating the composition of reaction solvents is efficient in controlling CD bandages and thus modulating multicolored emitting CDs or long wavelength-emissive CDs. The CDs could be directly synthesized using different solvents from the same precursor or may be synthesized CDs dispersed in different solvents to observe the tunable property (Song et al., 2019)-(Bai et al., 2019; Jing et al., 2019). For example, Tian et al. (2017) prepared all colour emitting CD using citric acid, urea as raw materials and three different solvents (water, glycerol, and dimethyl formamide) via a solvothermal method. Similarly, Yang adopted a solvothermal route by using citric acid, L-serine and monoethanolamine as the precursors and DMF as solvent to prepare blue green to dark green photoluminescent nitrogen doped CDs. The same precursors with water as the solvent allowed the preparation of blue fluorescence under UV light irradiation and showed the yellow color in visible light. Gao et al., found that C-Dots synthesized from citric acid (carbon source) and formamide (nitrogen source) exhibited dispersion solventdependent absorption and emission (Gao et al., 2018). The absorption and emission spectra of the C-Dots dispersed in four types of solvents like water, $\mathrm{N}, \mathrm{N}$-di-methylformamide (DMF), dimethyl sulfoxide (DMSO) and methanol produce multi-colour emissions (Gao et al., 2018). Water as a solvent generated blue dominated excitation as it cannot produce longwavelength while the other three solvents can generate longwavelength emission (redshift excitation wavelength). Thus, it is worth saying that the tunable bandgap may attribute from the solvents molecules.

Other than that, Zhang et al., have prepared four types of C-Dots from ethanol, n-butanol, domestic candle and benzene through the combustion process in four organic solvents (acetone, ethanol, benzene and petroleum ether) (Zhang et al., 2019). The prepared C-Dots have different absorption bands in different solvents but the different prepared C-Dots have the same absorption band in the same solvent. For instance, the absorption band of the four C-Dots in the ethanol and petroleum ether located at $200 \mathrm{~nm}$ while in the benzene and acetone it is shifted to 280 and $320 \mathrm{~nm}$. The absorption band showed fine emission peak when dispersed in the strong polarity of organic 
TABLE 3 | C-Dots doped with different element and their maximum emission wavelength.

\begin{tabular}{|c|c|c|c|c|c|c|}
\hline Doping element & $\begin{array}{l}\text { Synthesis } \\
\text { method }\end{array}$ & Carbon source & Doping agent & $\begin{array}{c}\text { Maximum } \\
\text { emission } \\
\text { wavelength }(\mathrm{nm})\end{array}$ & $\begin{array}{l}\text { Quantum } \\
\text { yields } \\
(\%)\end{array}$ & Ref \\
\hline \multirow[t]{3}{*}{ Nitrogen } & Solvo-thermal & Phenylenedi-amines & - & $435-604$ & $4.8-20.6$ & Jiang et al. (2015) \\
\hline & Hydro-thermal & Dwarf banana peel & - & 445 & 23 & $\begin{array}{l}\text { Atchudan et al. } \\
\text { (2020) }\end{array}$ \\
\hline & Micro-wave & Trisodium citrate dihydrate & Urea & $410-500$ & 80.7 & Zhang et al. (2020) \\
\hline $\begin{array}{l}\text { Phosphorus/ } \\
\text { nitrogen }\end{array}$ & Micro-wave & $\begin{array}{l}\text { Citric acid }(\mathrm{CA}) \text { and malic } \\
\text { acid }(\mathrm{MA})\end{array}$ & $\begin{array}{l}\text { Ethylenedi-amine }(\mathrm{N}) \text {, } \\
\text { phosphoric acid }(p)\end{array}$ & $\begin{array}{c}453.9-456.8(\mathrm{CA}) \\
453.9-514.5(\mathrm{MA})\end{array}$ & $\begin{array}{l}\sim 40(\mathrm{CA}) \\
\sim 14(\mathrm{MA})\end{array}$ & Zhi et al. (2018) \\
\hline Sulfur & Solvo-thermal & O-phenylenediamine, DMF & Thiourea (S) & 525-625 & $5.07-74.63$ & Gao et al. (2020) \\
\hline
\end{tabular}

solvents like acetone while in the weaker polarity of solvents (ethanol and benzene), the emission is obscured. It was also reported that the fluorescence emissions band also relied on the length of the carbon chain of the precursors. To conclude, the solvent-dependent emission was attributed to interaction between molecular states and solvents thereby influencing the optical bandgap.

\section{Effect of Raw Materials}

The precursor molecules have great effect on the properties of the C-Dot in terms of the fluorescence intensity enhancing and the photoluminescent colors regulation, etc. However, the precise relationship between precursor molecules and special properties of C-Dots remains unclear at present. As reported in the preceding part of the text, it can be seen clearly that the reaction precursors indeed have an influence on the fluorescence of prepared C-Dots. For example, among various nitrogen sources, formamide is famous for the successful preparation of red-emissive C-Dots, which can not only act as nitrogen source but also serve as a solvent in the solvothermal process.

\section{Large Scale Synthesis of C-Dots and Challenges}

Large scale synthesis of C-Dots is highly desired owing to their broad and practical applications. Most of the synthetic methods (Chen et al., 2010), (Bhunia et al., 2013) available currently allowed the production of C-Dots in large quantity (Gram scale) using orange juice (Sahu et al., 2012), chicken eggs (Wang et al., 2012) and ground coffee (Hsu et al., 2012). Compared to using liquid biomass, the use of solid biomass provides a better option for the scale up due to their diversity, amount available, much longer shelf life and more convenient scalability in quantity. Alternatively, using molecular precursors would be another strategy to consider for producing C-Dots with relatively high yields (Zhang and Yu, 2016). The operating condition, source and composition of the biomass have great influence on the final yield. Most recently, hydrothermal method was used to prepare C-Dots from yeast extract powder on a large scale with $65.8 \%$ yield in 1 day at low reaction temperature of $140^{\circ} \mathrm{C}$ (Zhu et al., 2020). The high yield was attributed to the hydrolytic breakdown of proteins and cellulose of yeast extract powder followed by the aggregation in hydrolysates at low temperature. Thus, more yeast extract powder was involved in the reaction process when the reaction time prolongs and contributed to an increase in reaction yield. Nevertheless, it was found that the reaction volumes and feeding mass do not vary the production yield and particle size of C-Dots significantly in a scale up synthesis study using rapeseed bee pollen (Zhang et al., 2015).

While there are literatures reported for large scale C-Dots production, no pilot/full scale production of C-Dots has been reported so far. Due to the low quantum yield and product yield of prepared C-Dots, the cost of source and huge amount of industrial availability of cheap raw materials is crucial for future scale up. In this regards, even though biomass and its derivatives have the advantages of availability, low cost and renewability, the complex precursor composition of biomass might contribute to C-Dots heterogeneity. The use of different biomass precursors might result in the accidental incorporation of trace non-metallic or metallic doping in the synthesis process, and consequently modify the structure and properties of the prepared C-Dots. Moreover, the diversity in the composition of same biomass source but different origin might influence the product quality and consistency. As such, comprehensive and detailed characterization of starting materials is required to ensure the consistency of precursors for reproducibility of C-Dots. At present, one of the most major and vital concerns in the synthesis of biomass derived C-Dots is the lack of a systematic and scalable synthesis procedure to produce high performance C-Dots with desirable structures. Additionally, the exact formation mechanism of biomass derived C-Dots is still unclear due to non-standard synthetic pathways and impurities. Therefore, for large-scale production of useful C-Dots through an efficient route, effects of precursors and reaction conditions (e.g., temperature, time, solvent) on the performance of C-Dots should be systematically explored.

\section{APPLICATIONS OF C-DOTS}

The need for green materials have become a necessity in the modern era of nanoscale materials. C-Dots are very promising for many applications due to their unique blend of properties. C-Dots emerge as an important research subject that is still experiencing rapid progress as reported by abundant scientific studies of recent times. In recent years, many natural resources such as honey, prawn shells, pear juice, kiwi fruit and coriander 
leaves have been adopted as carbon sources for the synthesis of C-Dots. Due to numerous major benefits of C-Dots, including their convenient synthesis, low cost, good renewability, colorful PL and excellent biocompatibility, scientists were inspired to develop new materials with new applications and low impact on the environment. Biomass derived C-Dots via facile and inexpensive systhesis route has profound contributions to the Sustainable Development Goals (SDGs) including energy conversion (SDG 7), the treatment of environmental pollutant (SDG 6), health (SDG 3) and food (SDG 2) which are explained in detail in the following sections.

\section{Energy Conversion and Electronic Devices}

Carbon materials are abundance in nature, high in electrical conductivity and chemical stability. These properties make carbon materials the ideal candidates as the electrode materials for lithium and sodium ion batteries. C-Dots synthesized with semiconductor, can act as surface stabilizer for active electrode material. For example graphene quantum dot-coated $\mathrm{VO}_{2}$ array electrode exhibited a high lithium capacity retention of $94 \%$ after 1,500 cycles (Chao et al., 2015). The unique properties of excitation-dependent or excitation-independent fluorescence emission and size-dependet fluorescence emission of C-Dots have been used for application in solar cells (Zhang et al., 2015). Grass was used to synthesize C-Dots that significantly enhanced the conversion efficiency of C-Dots sentitized aqueous solar cells. In this work, C-Dots derived from other waste materials such as glucose and chitosan were functionalized with the surface groups in the waste materials to form hybrid materials to be used in solid-state nanostructured solar cells (Briscoe et al., 2015). The performance of the solar cells is highly dependent on the functional groups on the C-Dots during the synthesis process. The charge transport within the layer of the hybrid materials also determines the efficiency of solar cell. Huang et al. (2020) reported the use of allium fistulosum, a spices vegetable widely grown in China to synthesize nitrogen self-doped C-Dots as quantum dots sensitizer in solar cells. Components of the allium fistulosum such as carbohydrate, cellulose and crude protein were hydrolyzed into glucose and amino acid via hydrothermal treatment. These hydrolysis products generated during the hydrothermal reaction become the precursors for the preparation of C-Dots, while the amino acid provides the nitrogen element for the doping. The influence factors on the photoelectric properties such as C-Dots and the sensitized time were carefully investigated. It is found that the photoelectric properties of the solar cells depends on the particle size, energy level structure, doping atoms as well as the preparation method of C-Dots.

Demand for electromobility has sparked intense quest for high energy storage systems to overcome the energy density limitations of conventional supercapacitors. Graphene has gained most attention for charge storage because of its ultrahigh surface area and superior conductivity (Tan et al., 2020), yet the practical specific capacitance of graphene is rather low due to the aggregation of graphene layers, which increase the packing density and impede ion accessibility. This challenge can be resolved by utilizing C-Dots as the spacers.
Electrodes fabricated from C-Dots/reduced graphene oxide (rGO) composites derived from natural carbon precursor such as orange juice (Tibodee et al., 2020) and cauliflower leaf waste (Hoang et al., 2019) exhibited high specific capacitance and superior cycling stability. The high capacitance was greatly depending on the role of the C-Dots as the effective spacers in preventing restacking of graphene nanosheets, leading to greater surface area and pore volume. Detailed study by Hoang (Hoang et al., 2019) revealed that doping of nitrogen influence the active sites for pseudo-capacitance caused by oxygen/nitrogen functional groups, charge transfer resistance and proton diffusivity in acidic electrolyte, resulted in enhanced the electrochemical characteristics of rGO. Praneerad and coworkers (Praneerad et al., 2019) has shown that C-Dots are effective dopant for improving electrode properties and the supercapasitor performances. In their work, C-dots from durian peel waste was prepared by pyrolysis method and was used as dopant to construct a composite electrode using poly (vinylidene fluoride) with a specific capacitance of $60 \mathrm{~F} \cdot g-1$, much higher than that of the pure activated carbon electrode. Further investigation revealed that the capacitance improvement was due to the introduction of high surface area C-Dots and pseudocapasitive behaviors by the surface functional groups of C-Dots.

C-Dots have great potential to improve smart electronic displays systems in optoelectronic devices. The ease of surface modifications, tunable PL emissions and doped chemical elements are the examples of effective measures for applying C-Dots in light emitting diodes (LEDs). The most common phosphors for commercial LEDs primarily depend on rareearth inorganic materials that are expensive and have potential toxicity to the environment (Homann et al., 2018). Compared to toxic starting materials, LEDs that are made up from C-Dots is promising green initiative, with high stability and low cost. Sarswat and Free (2015) produced multicolor, highly luminescent C-Dots to fabricate LEDs from food, beverages and combustion wastes. Gong et al. (2020) synthesized multiemissive C-Dots toward white LEDs from the extract of mango leaves through one-step microwave heating, producing emitting color from blue to yellow. Coated on a commercial $365 \mathrm{~nm}$ LED chip, the C-Dots showed greenish white light with CIE coordinates of $(0.37,0.44)$. Strategies such as $\mathrm{N}$-doping, surface passivation, and functionalization can be used to enhance the photoluminescence properties and stability.

\section{Sensing of Pollutants and Toxic Chemicals in Food}

The ever increasing populations is causing the urgent demand for the wastewater remediation due severe water scarcity. This has become a more pressing issue with the various industrial activities including those from the textile industries by discharging chemically stable and non-biodegradable toxic organic dyes into aquatic environments. The C-Dots demonstrates to be an ideal materials in sensing heavy metals in environmental pollutants. Several C-Dots have been developed for metal ions, anions, and molecules as direct fluorescent sensors. $\mathrm{Fe}^{3+}$ is the 
most commonly observed in the process of ion detection and relatively few other ions such as $\mathrm{Hg}^{2+}$ (Pourreza and Ghomi, 2019), $\mathrm{Ag}^{+}$(Zhong et al., 2017) and $\mathrm{Cu}^{2+}$ (Rong et al., 2017). $\mathrm{Fe}^{3+}$ are the most frequently observed ions because functional groups such as amino groups, carboxyl groups and hydroxyl groups are typically present on the C-Dots layer. These functional groups can be coupled effectively with iron ions, leading to fluorescence quenching. Orange peel, ginkgo biloba leaves, sweet potato and other diverse biomass waste are commonly used to synthesize C-Dots for iron detection. Shen et al. (2017) reported a facile synthesis from a sweet potato for preparing C-Dots by hydrothermal treatment. The prepared C-Dots was quenched by $\mathrm{Fe}^{3+}$ ion with a limit of detection of $0.32 \mu \mathrm{M}$ throughout a linear concentration $(1-100 \mu \mathrm{M})$. The researchers proposed that the fluorescence quenching by the $\mathrm{Fe}^{3+}$ ions attributed by the changes in the electronic structure of the C-Dots when the hydroxyl groups on the C-Dots surface is interacting with the iron ions (Shen et al., 2017). The fluorescence quenching in many sources means any process reduces the fluorescence intensity of given materials through which the fluorescence molecules interact with the quencher molecules (Callis, 2014). Furthermore, Khan et al. (2019), prepared nitrogen-doped C-Dots through a hydrothermal method of red lentils which act as carbon precursor provides a strong response to $\mathrm{Fe}^{3+}$ ions and stimulates the fluorescence of C-Dots to quench. The reported detection limit for sensitive and selective $\mathrm{Fe}^{3+}$ ions is $0.10 \mu \mathrm{M}$ with a concentration range of $2-20 \mu \mathrm{M}$. Similar work also reported by using Lycii Fructus (fruits) as the raw material through a hydrothermal synthesis to detect $\mathrm{Fe}^{3+}$ ions selectively and sensitively with a low detection limit of $0.021 \mu \mathrm{M}$. It is proposed that the fluorescence quenching may due to the inner filter effect (IFE) induced by the $\mathrm{Fe}^{3+}$.

Besides the detection of $\mathrm{Fe}^{3+}$, the detection of some heavy and poisonous metal ions using C-Dots is increasingly common in recent years. $\mathrm{Hg}^{2+}$ ion is highly toxic as it is one of most poisonous, harmful and omnipresent pollutants. Pourreza and Ghomi, reported the green synthesis of C-Dots from leaves of Prosopis juliflora as a dual off-on fluorescence probe for sensing mercury (II) ions via hydrothermal route (Pourreza and Ghomi, 2019). The C-Dots have an outstanding selectivity and sensitivity towards $\mathrm{Hg}^{2+}$ with a low detection limit of $1.26 \mathrm{ng} \mathrm{ml}^{-1}$ under ideal conditions. In the system, the fluorescence of the C-Dots was quenched by the addition of different concentrations (in the range of 5-500 $\mathrm{ng} \mathrm{ml}^{-1}$ ) of $\mathrm{Hg}^{2+}$ ions. A similar study also has been conducted by Li et al. to prepare C-Dots from green carbon sources known as Hongcaitai (vegetables) via a hydrothermal method for $\mathrm{Hg}^{2+}$ ions detections (Li et al., 2018). The fluorescence of the C-Dots quenched through increasing the $\mathrm{Hg}^{2+}$ concentrations (from 0.2 to $200 \mu \mathrm{M}$ ) with a detection limit of $0.06 \mu \mathrm{M}$. The efficient sensing may probably be due to the good affinity of $\mathrm{Hg}^{2+}$ with more sulphur-containing functional groups on the surface of the C-Dots. The interaction between the functional groups and the mercury ions may facilitate the electron transfer in the C-Dots leading the C-Dots to be an excellent sensor for $\mathrm{Hg}^{2+}$.

Using kelp as the primary carbon source with ethylenediamine as the nitrogen dopant are used to prepare C-Dots by using the microwave-irradiation process by Zhao et al. (2019). To detect cobalt ions in water samples, the synthesized C-Dots successfully showed high selectivity and sensitivity of $\mathrm{Co}^{2+}$ ions detection with a detection limit of $0.39 \mu \mathrm{mol} / \mathrm{L}$ in the concentration range of $1-200 \mu \mathrm{mol} / \mathrm{L}$. These points proved that C-Dots is an excellent nanosensor for the detection of heavy metals ions pollutants of environmental significance through fluorescence quenching.

On the other hand, excessive use of veterinary drugs, antibiotics and pesticides in poultries and agricultural activities poses a serious threat to the animal bodies, human health and environment. Antibiotic residues such as tetracycline (Jayaweera et al., 2019), (Guo et al., 2020) and amoxicillin (Wang et al., 2018) have been detected using C-Dots-based composite sensor through quenching of fluorescence (Guo et al., 2020) or enhancement (Wang et al., 2018) and inner filter effect (Jayaweera et al., 2019). Traces of estrogen drugs that were used in animals, birds for fast growth can also be detected by C-Dots-based sensor very effectively (Zhao et al., 2018). Additionally, pesticides that is widely found in water, soil, sewage sludge, sediment and aquatic biota increase the risk of different diseases such as mental confusion, eczema, reproductive toxicity, damage liver, kidney, neural and immune systems in human beings (Jayaraj et al., 2016). The detection of herbicide (pretilachlor) by C-Dots prepared from water hyacinth has also been reported (Deka et al., 2019). Wool-based microwaved assisted C-Dots sensor for detecting glyphosate based on the inner filter effect was also demonstrated (Wang et al., 2016). However, current C-Dots detection approach suffers from poor specificity with the target analyte in the detection of antibiotics and pesticides, therefore precise structure of C-Dots, surface functionalization and control during the synthesis process are important.

\section{Bioimaging}

C-Dots has great potential as agents for bioimaging. Fluorescence imaging has become an effective technique for visualizing biological processes within living cells due to benefits including lack of risk of radioactivity, higher sensitivity, better spatial resolution and increased high-performance capability. Several research groups have used many raw materials over the past few years to prepare a wide range of bioimaging C-Dots. The precursor origin is wide-ranging and easily available such as common beverages, food and waste.

Leaves are commonly available from the garden or industrial plantation. Bhatt et al. synthesized C-Dots under hydrothermal synthesis from Tulsi leaves with no other reagents used (Bhatt et al., 2018). The C-Dots exhibited low toxicity and emitted blue, yellow and red fluorescent images of bacteria cells during cellular imaging experiments (B.subtilis and E-coli). This implied that carbon dots successfully penetrated the cell membrane, making them potential imaging agents. Therefore, in contrast with traditional dyes and quantum dots, C-Dots act as a better alternative for cell imaging.

At the same time, edible fruits are also suitable material for C-Dots synthesis. For example, Ramezani, Qorbanpour and Rahbar used quince fruit to synthesize C-Dots under microwave irradiation as an effective bioimaging agent for 
HT-29 cells under inverted fluorescence microscope at a concentration of $1,000 \mu \mathrm{g} \mathrm{ml}^{-1}$ (Ramezani et al., 2018). The synthesized C-Dots can be used in biosensors as well as in bioimaging due to low toxicity.

Besides that, Sun et al. (2017), also reported the green synthesis of C-Dots from Lycii Fructus fruit, which later showed excellent multicolour (bright blue, glaucous and green) cell imaging with HeLa cells under an upright fluorescence microscope. These findings show that C-Dots were membrane-permeable although the C-Dots concentrations were increased to $200 \mu \mathrm{g} /$ $\mathrm{ml}$. The multicolor emission of CDs in bioimaging application was better than traditional fluorescent protein with a single fluorescent characteristic.

\section{Biocide or Antimicrobial Agent}

The term to describe biocide is commonly used as a synonym for a disinfectant/sanitizer or antimicrobial agent. (Ribeiro et al., 2018). C-Dots antimicrobial activity has recently gained attention due to its excellent optical properties, low toxicity to mammalian cells, and multivalent microorganism interaction. Besides, photoexcited C-Dots can create reactive oxygen species (ROS) known to kill or inhibit microorganisms as shown in Figure 6.

Figure 6. Two types of bacteria, Escherichia coli (Gramnegative) and Staphylococcus aureus (Gram-positive) were used to test the ability of the C-Dots, derived from Henna plant via hydrothermal synthesis without adding chemical reagent as an antibacterial agent at different concentrations of C-Dots (Shahshahanipour et al., 2019). The results showed that in much lower concentrations $(100 \mu \mathrm{g} / \mathrm{ml})$, C-Dots from Henna plant killed Gram-positive and Gram-negative bacteria like an antibiotic drug. C-Dots caused membrane damage or produced free radicals and oxidizing spices leading to bacterial death due to their small size and the high surface-to-volume ratio (Hajipour et al., 2012). Furthermore, the toxicity of nanoparticles to bacteria, which correlated to the structure, volume, surface and bacterial functional groups of C-Dots disrupted and destroyed major cellular components of the bacteria's vital actions (Shahshahanipour et al., 2019).

Jijie et al. (2018) studied a simple hydrothermal process of citric acid and ethylenediamine to synthesis amine-functionalized C-Dots $\left(\mathrm{CDs}-\mathrm{NH}_{2}\right)$ and conjugated with ampicillin (AMP) to produce C-Dots-AMP nanostructures. The results showed the potential of CDs-AMP as an effective platform for the eradication of bacteria. The conjugated C-Dots-AMP has inhibited the growth of E. coli cells in the lowest concentration of $14 \mu \mathrm{g} \mathrm{ml}^{-1}$ with the exposure of visible light to improve its bactericidal activity. The positively charged C-Dots were found to have the most bactericidal activity, whereas the negatively charged and uncharged C-Dots had almost no bactericidal activity. A mechanistic study revealed that the bacteria showed characteristic markers of apoptosis in treatment with C-Dots charged positively and negatively, similar to those found in common antibiotic treatment.

Jhonsi et al. (2018) reported the studies of fluorescent C-Dots synthesized from tamarind towards antimicrobial activity and fungal strain. Disc diffusion analysis determined the antimicrobial activity of the C-Dots. The findings revealed that C-Dots from tamarind successfully inhibited bacteria growth in a concentration-dependent manner. The antibacterial and antifungal activities increased linearly with increased concentrations of C-Dots $(2.4,5$ and $10 \mathrm{mg} / \mathrm{ml})$ as the calculated inhibition area ranged from 7 to $12 \mathrm{~mm}$ for all bacterial species and $14 \mathrm{~mm}$ for fungal strain. Under confocal microscopy, fluorescent properties of C-Dots were evaluated directly without any fluorescent tagging. Fungal cells only fluorescent when attached to the C-Dots, while cells without C-Dots do not have fluorescence properties.

Wang et al. (2017) worked on the use of silane binding agents for grafting C-Dots with silver nanoparticles (AgNPs) to develop a new approach to create Ag-nanoclustes-C-shell nanocomposites (Ag@C). The Ag@C nanocomposites were used to evaluate the performance of the antibacterial behaviour and cell toxicity against both Gram-positive $S$. aureus bacteria and Gram-negative E. coli bacteria. The antimicrobial assay was conducted by using the disc diffusion process with several different concentrations of Ag@C nanocomposites such as $0.25,0.5$, and $1 \mathrm{mg} / \mathrm{ml}$. The Ag@C nanocomposites have potent bactericidal result towards both positive and negative bacteria ( $S$. aureus and E. coli) as Wang et al., inferred that silver ions from silver cores could be emitted via carbon shells due to the entry of the solution where it can prolong the release time of silver (Ag) ions, thus retaining a sustained antibacterial activity. Moreover, damage to DNA and mitochondria would boost reactive oxygen species (ROS) and caused cell death (Li et al., 2018) by which was done by AgNPs or silver salts. On top of that, Ag@C nanocomposites showed no toxicity to hamster ovarian cells due to successful antibacterial concentrations of the Ag@C nanocomposites.

Raina et al. (2020) studied bactericidal behavior by using acetone leaf extract of Cannabis sativa (weed plant) as the carbon precursor with $\mathrm{AgNO}_{3}$ solution to synthesis silver C-Dots via one-step pyrolysis approach. The study showed that an effective difference in antibacterial activity between different concentrations of silver C-Dots used towards these microbes (E.coli and S. aureus) by evaluating it through a disc diffusion and microplate assay. About $90 \%$ of these microorganisms have been killed by the synthesized silver C-Dots at a minimum concentration (MIC) of $42 \mu \mathrm{g} / \mathrm{ml}$ that prevented the growth of bacterial. Yet, no concentration of silver C-Dots could be identified as significant MIC as the maximum killing at a concentration of $25 \mathrm{mg} / \mathrm{ml}$ against dental microflora due to the heterogeneous nature of the culture showed varying susceptibility to silver C-Dots (Shivaji et al., 2018).

Through the hydrothermal process Lakshmanan et al. have synthesized C-Dots using the orange waste peel to develop it as an antibacterial agent (Lakshmanan et al., 2021). The antibacterial test from C-Dots was tested on both Gram-negative bacteria such as Vibrio cholera, Pseudomonas eruginosa and Escherichia coli and Gram-positive bacteria consisted of Staphylococcus aureus and Bacillus cereus by disc diffusion scheme. The inhibition zone was formed against the bacterial strains where inhibition zone of greater than $6 \mathrm{~mm}$ implied an antibacterial activity. On the other hand, the antibacterial activity was considered low if the diameter of inhibition was less than $6 \mathrm{~mm}$. In the presence of moisture, C-Dots contact with bacterial cells developed highly reactive 
oxygen species (hydroxyl radicals, superoxide) which infiltrated the cell wall and lead to death by bacteria (Alavi and Karimi, 2019). As a result, C-Dots have successfully inhibited the growth of five pathogens, particularly against Pseudomonas aeruginosa bacteria as it showed high antibacterial characteristic as compared to other pathogenic bacteria.

\section{CONCLUSIONS AND FUTURE OUTLOOK}

This review highlighted the recent progress in the field of C-Dots focusing on the analysis of structure, composition, synthesis routes, the use of raw materials as a carbon source, strategies to tune optical properties and applications of C-Dots in sensing metal ions, bioimaging and as antibacterial agent. In addition, we summarized different C-Dots synthesizing approaches to identify the advantages and disadvantages of the methods, with a particular focus on the bottom-up method. Among all the synthetic processes, hydrothermal treatment of C-dots was the most common technique due to its inexpensive nature, practicality and convenience. The synthesis routes are usually simple and can be prepared from a broad range of carbon sources e.g. chemicals, renewable materials and even wastes. However, there is limited documentation of biomass C-Dots with high quantum yield (QY). Some strategies to tune the fluorescence emission, excitation toward longer wavelength include effects of particle size, surface states, heteroatom doping and the effect of solvent on the optical properties of C-Dots were also reported. Further research and development are still highly desirable in this field. An effective method for the

\section{REFERENCES}

Alavi, M., and Karimi, N. (2019). Biosynthesis of Ag and Cu NPs by secondary metabolites of usnic acid and thymol with biological macromolecules aggregation and antibacterial activities against multi drug resistant (MDR) bacteria. Int. J. Biol. Macromol. 128, 893-901. doi:10.1016/j.ijbiomac.2019. 01.177

Amjad, M., Iqbal, M., Faisal, A., Junjua, A. M., Hussain, I., Hussain, S. Z., et al. (2019). Hydrothermal synthesis of carbon nanodots from bovine gelatin and PHM3 microalgae strain for anticancer and bioimaging applications. Nanoscale Adv. 1 (8), 2924-2936. doi:10.1039/c9na00164f

An, Z., Furmanchuk, A. O., Ramachandramoorthy, R., Filleter, T., Roenbeck, M. R., Espinosa, H. D., et al. (2014). Inherent carbonaceous impurities on arcdischarge multiwalled carbon nanotubes and their implications for nanoscale interfaces. Carbon 80 (1), 1-11. doi:10.1016/j.carbon.2014.07.069

Ankireddy, S. R., and Kim, J. (2018). Highly selective and sensitive detection of calcium (II) ions in human serum using novel fluorescent carbon dots. Sensors Actuators B: Chem. 255, 3425-3433. doi:10.1016/j.snb.2017.09.172

Arora, N., and Sharma, N. N. (2014). Arc discharge synthesis of carbon nanotubes: comprehensive review. Diamond Relat. Mater. 50, 135-150. doi:10.1016/j. diamond.2014.10.001

Arul, V., Edison, T. N., Lee, Y. R., and Sethuraman, M. G. (2017). Biological and catalytic applications of green synthesized fluorescent $\mathrm{N}$-doped carbon dots using Hylocereus undatus. J. Photochem. Photobiol. B, Biol. 168, 142-148. doi:10.1016/j.jphotobiol.2017.02.007

Arul, V., and Sethuraman, M. G. (2018). Facile green synthesis of fluorescent $\mathrm{N}$-doped carbon dots from Actinidia deliciosa and their catalytic activity and cytotoxicity applications. Opt. Mater. 78, 181-190. doi:10.1016/j.optmat.2018. 02.029 large-scale preparation of high-quality C-Dots with broad visible emission is to be identified in future research. The use of waste materials gives the possibility of large-scale C-Dots preparation with the focus more on the correlation of material structure and properties with photoluminescence mechanism efficiency. It is hopeful that through the related summaries and reviews, more progress can be made with C-Dots for wider applications.

\section{AUTHOR CONTRIBUTIONS}

All authors listed have contributed equally and made a substantial, direct and intellectual contribution to the work, and approved it for publication.

\section{FUNDING}

This work was supported by GIP (600-IRMI 5/3/GIP (070/ 2019)), Bestari (600-IRMI/DANA 5/3/BESTARI (115/2018)), 600-IRMI/GPK 5/3 (153/2020) and GRR (600-RMC 5/3 GRR $(005 / 2020))$ provided by the Universiti Teknologi MARA.

\section{ACKNOWLEDGMENTS}

The authors would like to thank Institute of Quality \& Knowledge Advancement (InQKA), Universiti Teknologi MARA, Malaysia for providing assistance in reviewing the manuscript.

Arumugham, T., Alagumuthu, M., Amimodu, R. G., Munusamy, S., and Iyer, S. K. (2020). A sustainable synthesis of green carbon quantum dot (CQD) from Catharanthus roseus (white flowering plant) leaves and investigation of its dual fluorescence responsive behavior in multi-ion detection and biological applications. Sustainable Mater. Tech. 23, e00138, doi:10.1016/j.susmat.2019. e00138

Atchudan, R., Edison, T. N. J. I., Aseer, K. R., Perumal, S., Karthik, N., and Lee, Y. R. (2018). Highly fluorescent nitrogen-doped carbon dots derived from Phyllanthus acidus utilized as a fluorescent probe for label-free selective detection of $\mathrm{Fe} 3+$ ions, live cell imaging and fluorescent ink. Biosens. Bioelectron. 99, 303-311. doi:10.1016/j.bios.2017.07.076

Atchudan, R., Edison, T. N. J. I., Chakradhar, D., Perumal, S., Shim, J.-J., and Lee, Y. R. (2017). Facile green synthesis of nitrogen-doped carbon dots using Chionanthus retusus fruit extract and investigation of their suitability for metal ion sensing and biological applications. Sensors Actuators B: Chem. 246, 497-509. doi:10.1016/j.snb.2017.02.119

Atchudan, R., Edison, T. N. J. I., Perumal, S., Muthuchamy, N., and Lee, Y. R. (2020). Hydrophilic nitrogen-doped carbon dots from biowaste using dwarf banana peel for environmental and biological applications, Fuel, 275, 117821. doi:10.1016/j.fuel.2020.117821

Atchudan, R., Edison, T. N. J. I., Perumal, S., Vinodh, R., and Lee, Y. R. (2019). Betel-derived nitrogen-doped multicolor carbon dots for environmental and biological applications. J. Mol. Liquids 296, 111817. doi:10.1016/j.molliq.2019. 111817

Atchudan, R., Edison, T. N. J. I., Sethuraman, M. G., and Lee, Y. R. (2016). Efficient synthesis of highly fluorescent nitrogen-doped carbon dots for cell imaging using unripe fruit extract of Prunus mume. Appl. Surf. Sci. 384, 432-441. doi:10. 1016/j.apsusc.2016.05.054

Bai, J., Ma, Y., Yuan, G., Chen, X., Mei, J., Zhang, L., et al. (2019). Solventcontrolled and solvent-dependent strategies for the synthesis of multicolor 
carbon dots for $\mathrm{pH}$ sensing and cell imaging. J. Mater. Chem. C 7 (31), 9709-9718. doi:10.1039/c9tc02422k

Bajpai, S. K., D'Souza, A., and Suhail, B. (2019). Blue light-emitting carbon dots (CDs) from a milk protein and their interaction with Spinacia oleracea leaf cells. Int. Nano Lett. 9 (3), 203-212. doi:10.1007/s40089-019-0271-9

Bandi, R., Devulapalli, N. P., Dadigala, R., Gangapuram, B. R., and Guttena, V. (2018). Facile conversion of toxic cigarette butts to n,s-codoped carbon dots and their application in fluorescent film, security ink, bioimaging, sensing and logic gate operation. ACS Omega 3 (10), 13454-13466. doi:10.1021/acsomega. $8 \mathrm{~b} 01743$

Bandi, R., Gangapuram, B. R., Dadigala, R., Eslavath, R., Singh, S. S., and Guttena, V. (2016). Facile and green synthesis of fluorescent carbon dots from onion waste and their potential applications as sensor and multicolour imaging agents. RSC Adv. 6 (34), 28633-28639. doi:10.1039/c6ra01669c

Bao, L., Zhang, Z. L., Tian, Z. Q., Zhang, L., Liu, C., Lin, Y., et al. (2011). Electrochemical tuning of luminescent carbon nanodots: from preparation to luminescence mechanism. Adv. Mater. Weinheim 23 (48), 5801-5806. doi:10.1002/adma.201102866

Barman, M. K., and Patra, A. (2018). Current status and prospects on chemical structure driven photoluminescence behaviour of carbon dots. J. Photochem. Photobiol. C: Photochem. Rev. 37, 1-22. doi:10.1016/j.jphotochemrev.2018.08.001

Bhamore, J. R., Jha, S., Singhal, R. K., Park, T. J., and Kailasa, S. K. (2018). Facile green synthesis of carbon dots from Pyrus pyrifolia fruit for assaying of $\mathrm{Al} 3+$ ion via chelation enhanced fluorescence mechanism. J. Mol. Liquids 264, 9-16. doi:10.1016/j.molliq.2018.05.041

Bhartiya, P., Singh, A., Kumar, H., Jain, T., Singh, B. K., and Dutta, P. K. (2016). Carbon dots: chemistry, properties and applications. J. Indian Chem. Soc. 93 (7), 759-766. doi:10.1039/C4TC00988F

Bhatt, S., Bhatt, M., Kumar, A., Vyas, G., Gajaria, T., and Paul, P. (2018). Green route for synthesis of multifunctional fluorescent carbon dots from Tulsi leaves and its application as $\mathrm{Cr}(\mathrm{VI})$ sensors, bio-imaging and patterning agents. Colloids Surf. B: Biointerfaces 167, 126-133. doi:10.1016/j.colsurfb.2018.04.008

Bhunia, S. K., Saha, A., Maity, A. R., Ray, S. C., and Jana, N. R. (2013). Carbon nanoparticle-based fluorescent bioimaging probes. Sci. Rep. 3-1473. doi:10. 1038/srep01473

Bi, J., Li, Y., Wang, H., Song, Y., Cong, S., Li, D., et al. (2017). Physicochemical properties and cytotoxicity of carbon dots in grilled fish. New J. Chem. 41 (16), 8490-8496. doi:10.1039/c7nj02163a

Briscoe, J., Marinovic, A., Sevilla, M., Dunn, S., and Titirici, M. (2015). Biomassderived carbon quantum dot sensitizers for solid-state nanostructured solar cells. Angew. Chem. Int. Ed. Engl. 54 (15), 4463-4468. doi:10.1002/anie. 201409290

Callis, P. R. (2014). Binding phenomena and fluorescence quenching. I: descriptive quantum principles of fluorescence quenching using a supermolecule approach. J. Mol. Struct. 1077, 14-21. doi:10.1016/j.molstruc.2014.04.050

Cao, J., An, X., and Han, S. (2020). Surface structure and fluorescence characteristics of concentrated carbon point. Colloids Surf. A: Physicochemical Eng. Aspects 586, 124201. doi:10.1016/j.colsurfa.2019.124201

Carbonaro, C., Corpino, M., Salis, O., Mocci, F., Thakkar, S. V., Olla, C., et al. (2019). On the emission properties of carbon dots: reviewing data and discussing models. J. Carbon Res. 5 (4), 60. doi:10.3390/c5040060

Chan, K. K., Yap, S. H. K., and Yong, K. T. (2018). Biogreen synthesis of carbon dots for biotechnology and nanomedicine applications. Nano-Micro Lett. 10 (4). doi:10.1007/s40820-018-0223-3

Chao, D., Zhu, C., Xia, X., Liu, J., Zhang, X., Wang, J., et al. (2015). Graphene quantum dots coated VO2 arrays for highly durable electrodes for Li and Na ion batteries. Nano Lett. 15 (1), 565-573. doi:10.1021/nl504038s

Chen, B., Li, F., Weng, W., Guo, H., Zhang, X., Chen, Y., et al. (2010). Large scale synthesis of photoluminescent carbon nanodots and their application for bioimaging. Nanscale, 207890. doi:10.1039/C2NR32675B

Chen, T. H., and Tseng, W. L. (2017). Self-Assembly of monodisperse carbon dots into high-brightness nanoaggregates for cellular uptake imaging and iron(III) sensing. Anal. Chem. 89 (21), 11348-11356. doi:10.1021/acs.analchem.7b02193

Choi, J., Kim, N., Oh, J.-W., and Kim, F. S. (2018). Bandgap engineering of nanosized carbon dots through electron-accepting functionalization. J. Ind. Eng. Chem. 65, 104-111. doi:10.1016/j.jiec.2018.04.018
Demchenko, A. P., and Dekaliuk, M. O. (2013). Novel fluorescent carbonic nanomaterials for sensing and imaging. Methods Appl. Fluoresc 1, 042001, doi:10.1088/2050-6120/1/4/042001

Dager, A., Uchida, T., Maekawa, T., and Tachibana, M. (2019). Synthesis and characterization of mono-disperse carbon quantum dots from fennel seeds: photoluminescence analysis using machine learning. Sci. Rep. 9 (1), 14004-14010. doi:10.1038/s41598-019-50397-5

De, B., and Karak, N. (2013). A green and facile approach for the synthesis of water soluble fluorescent carbon dots from banana juice. RSC Adv. 3 (22), 8286-8290. doi:10.1039/c3ra00088e

De, B., and Karak, N. (2017). Recent progress in carbon dot-metal based nanohybrids for photochemical and electrochemical applications. J. Mater. Chem. A. 5 (5), 1826-1859. doi:10.1039/C6TA10220D

De Medeiros, T. V., Manioudakis, J., Noun, F., Macairan, J.-R., Victoria, F., and Naccache, R. (2019). Microwave-assisted synthesis of carbon dots and their applications. J. Mater. Chem. C 7 (24), 7175-7195. doi:10.1039/c9tc01640f

Deka, M. J., Dutta, P., Sarma, S., Medhi, O. K., Talukdar, N. C., and Chowdhury, D. (2019). Carbon dots derived from water hyacinth and their application as a sensor for pretilachlor. Heliyon 5 (6), e01985. doi:10.1016/j.heliyon.2019. e01985

Dey, S., Govindaraj, A., Biswas, K., and Rao, C. N. R. (2014). Luminescence properties of boron and nitrogen doped graphene quantum dots prepared from arc-discharge-generated doped graphene samples. Chem. Phys. Lett. 595-596 (596), 203-208. doi:10.1016/j.cplett.2014.02.012

Diao, H., Li, T., Zhang, R., Kang, Y., Liu, W., Cui, Y., et al. (2018). Facile and green synthesis of fluorescent carbon dots with tunable emission for sensors and cells imaging. Spectrochimica Acta A: Mol. Biomol. Spectrosc. 200, 226-234. doi:10. 1016/j.saa.2018.04.029

Dias, C., Vasimalai, N., P. Sárria, M., Pinheiro, I., Vilas-Boas, V., Peixoto, J., et al. (2019). Biocompatibility and bioimaging potential of fruit-based carbon dots. Nanomaterials 9, 199-217. doi:10.3390/nano9020199

Ding, H., Yu, S. B., Wei, J. S., and Xiong, H. M. (2016). Full-color light-emitting carbon dots with a surface-state-controlled luminescence mechanism. ACS Nano 10 (1), 484-491. doi:10.1021/acsnano.5b05406

Don, C., Torres-mendieta, R., Pyatenko, A., Falomir, E., Ferna, M., and Gladys, M. (2018). Fabrication by laser irradiation in a continuous flow jet of carbon quantum dots for fluorescence imaging. ACS Omega 3 (3). 2735-2742. doi:10. 1021/acsomega.7b02082

Dong, X., Liang, W., Meziani, M. J., Sun, Y.-P., and Yang, L. (2020). Carbon dots as potent antimicrobial agents. Theranostics 10 (2), 671-686. doi:10.7150/thno. 39863

Dong, Y., Shao, J., Chen, C., Li, H., Wang, R., Chi, Y., et al. (2012). Blue luminescent graphene quantum dots and graphene oxide prepared by tuning the carbonization degree of citric acid. Carbon 50 (12), 4738-4743. doi:10.1016/ j.carbon.2012.06.002

D'souza, S. L., Chettiar, S. S., Koduru, J. R., and Kailasa, S. K. (2018). Synthesis of fluorescent carbon dots using Daucus carota subsp. sativus roots for mitomycin drug delivery. Optik (Stuttg). 158, 893-900. doi:10.1016/j.ijleo.2017.12.200

Fan, R.-J., Sun, Q., Zhang, L., Zhang, Y., and Lu, A.-H. (2014). Photoluminescent carbon dots directly derived from polyethylene glycol and their application for cellular imaging. Carbon 71, 87-93. doi:10.1016/j.carbon.2014.01.016

Fang, Q., Dong, Y., Chen, Y., Lu, C.-H., Chi, Y., Yang, H.-H., et al. (2017). Luminescence origin of carbon based dots obtained from citric acid and amino group-containing molecules. Carbon 118, 319-326. doi:10.1016/j.carbon.2017. 03.061

Favaro, M., Ferrighi, L., Fazio, G., Colazzo, L., Di Valentin, C., Durante, C., et al. (2015). Single and multiple doping in graphene quantum dots: unraveling the origin of selectivity in the oxygen reduction reaction. ACS Catal. 5 (1), 129-144. doi:10.1021/cs501211h

Gao, D., Liu, X., Jiang, D., Zhao, H., Zhu, Y., Chen, X., et al. (2018). Exploring of multicolor emissive carbon dots with novel double emission mechanism. Sensors Actuators B: Chem. 277. 373-380. doi:10.1016/j.snb.2018.09.031

Gao, D., Zhang, Y., Liu, A., Zhu, Y., Chen, S., Wei, D., et al. (2020). Photoluminescence-tunable carbon dots from synergy effect of sulfur doping and water engineering. Chem. Eng. J. 388, 124199. doi:10.1016/j.cej. 2020.124199 
Gao, D., Zhao, H., Chen, X., and Fan, H. (2018). Recent advance in red-emissive carbon dots and their photoluminescent mechanisms. Mater. Today Chem. 9, 103-113. doi:10.1016/j.mtchem.2018.06.004

Gedda, G., Lee, C.-Y., Lin, Y.-C., and Wu, H.-f. (2016). Green synthesis of carbon dots from prawn shells for highly selective and sensitive detection of copper ions. Sensors Actuators B: Chem. 224, 396-403. doi:10.1016/j.snb.2015.09.065

Genc, R., Alas, M. O., Harputlu, E., Repp, S., Kremer, N., Castellano, M., et al. (2017). High-capacitance hybrid supercapacitor based on multi-colored fluorescent carbon-dots. Sci. Rep. 7 (1), 11222-11234. doi:10.1038/s41598-017-11347-1

Gong, Y., Han, Y., Zhang, F., Zhai, M., Chen, X., Long, Q., et al. (2020). Color tuning of biomass-derived carbon nanodots by reaction temperature toward white light-emitting diodes. Nano 15 (12). doi:10.1142/s1793292020501593

Guo, F., Zhu, Z., Zheng, Z., Jin, Y., Di, X., Xu, Z., et al. (2020). Facile synthesis of highly efficient fluorescent carbon dots for tetracycline detection. Environ. Sci. Pollut. Res. Int. 27 (4), 4520-4527. doi:10.1007/s11356-019-06779-3

Guo, H., You, B., Zhao, S., Wang, Y., Sun, G., Bai, Y., et al. (2018a). Full-color tunable photoluminescent carbon dots based on oil/water interfacial synthesis and their applications. RSC Adv. 8 (42), 24002-24012. doi:10.1039/c8ra03723j

Guo, L., Li, L., Liu, M., Wan, Q., Tian, J., Huang, Q., et al. (2018b). Bottom-up preparation of nitrogen doped carbon quantum dots with green emission under microwave-assisted hydrothermal treatment and their biological imaging. Mater. Sci. Eng. C 84, 60-66. doi:10.1016/j.msec.2017.11.034

Hajipour, M. J., Fromm, K. M., Ashkarran, A., Jimenez de Aberasturi, D., de Larramendi, I. R., Rojo, T., et al. (2012). Antibacterial properties of nanoparticles. Trends Biotechnol. 30 (10), 499-511. doi:10.1016/j.tibtech.2012.06.004

He, G., Shu, M., Yang, Z., Ma, Y., Huang, D., Xu, S., et al. (2017). Microwave formation and photoluminescence mechanisms of multi-states nitrogen doped carbon dots. Appl. Surf. Sci. 422, 257-265. doi:10.1016/j.apsusc.2017.05.036

Hoan, B. T., Thanh, T. T., Tam, P. D., Trung, N. N., Cho, S., and Pham, V.-H. (2019). A green luminescence of lemon derived carbon quantum dots and their applications for sensing of V5+ ions. Mater. Sci. Eng. B 251, 114455. doi:10. 1016/j.mseb.2019.114455

Hoang, V. C., Nguyen, L. H., and Gomes, V. G. (2019). High efficiency supercapacitor derived from biomass based carbon dots and reduced graphene oxide composite. J. Electroanalytical Chem. 832, 87-96. doi:10. 1016/j.jelechem.2018.10.050

Homann, C., Krukewitt, L., Frenzel, F., Grauel, B., Würth, C., Resch-Genger, U., et al. (2018). NaYF4 :Yb,Er/NaYF4 core/shell nanocrystals with high upconversion luminescence quantum yield. Angew. Chem. Int. Ed. Engl. 57 (28), 8765-8769. doi:10.1002/anie.201803083

Hong, T.-Z., Xue, Q., Yang, Z.-Y., and Dong, Y.-P. (2016). Great-enhanced performance of $\mathrm{Pt}$ nanoparticles by the unique carbon quantum dot/ reduced graphene oxide hybrid supports towards methanol electrochemical oxidation. J. Power Sourc. 303, 109-117. doi:10.1016/j.jpowsour.2015.10.092

Hsu, P.-C., Shih, Z.-Y., Lee, C.-H., and Chang, H.-T. (2012). Synthesis and analytical applications of photoluminescent carbon nanodots. Green. Chem. 14 (4), 917-920. doi:10.1039/c2gc16451e

Hu, Q., Gong, X., Liu, L., and Choi, M. M. F. (2017). Characterization and analytical separation of fluorescent carbon nanodots. J. Nanomater. 2017, 1-23. doi:10.1155/2017/1804178

Hu, S., Trinchi, A., Atkin, P., and Cole, I. (2015). Tunable photoluminescence across the entire visible spectrum from carbon dots excited by white light. Angew. Chem. Int. Ed. Engl. 54 (10), 2970-2974. doi:10.1002/anie.201411004

$\mathrm{Hu}$, Y., Yang, J., Tian, J., Jia, L., and Yu, J.-S. (2014). Waste frying oil as a precursor for one-step synthesis of sulfur-doped carbon dots with $\mathrm{pH}$-sensitive photoluminescence. Carbon 77, 775-782. doi:10.1016/j.carbon.2014.05.081

Huang, P., Xu, S., Zhang, M., Zhong, W., Xiao, Z., and Luo, Y. (2020). Green allium fistulosum derived nitrogen self-doped carbon dots for quantum dot-sensitized solar cells. Mater. Chem. Phys. 240, 122158. doi:10.1016/j.matchemphys.2019.122158

Javan, H., Asghari, E., and Ashassi-Sorkhabi, H. (2019). Fabrication and electrochemical kinetics studies of reduced carbon quantum dots- supported palladium nanoparticles as bifunctional catalysts in methanol oxidation and hydrogen evolution reactions, Synth. Met., 254. 153-163. doi:10.1016/j. synthmet.2019.06.006

Jayaraj, R., Megha, P., and Sreedev, P. (2016). Organochlorine pesticides, their toxic effects on living organisms and their fate in the environment. Interdiscip. Toxicol. 9 (3-4), 90-100. doi:10.1515/intox-2016-0012
Jayaweera, S., Yin, K., and Ng, W. J. (2019). Nitrogen-doped durian shell derived carbon dots for inner filter effect mediated sensing of tetracycline and fluorescent ink. J. Fluoresc. 29 (1), 221-229. doi:10.1007/s10895-018-2331-3

Jeong, C. J., Lee, G., Insik, I., and In, S. Y. (2016). Concentration-mediated multicolor fluorescence polymer carbon dots. Luminescence 31 (3), 897-904. doi:10.1002/bio.3050

Jhonsi, M. A., Ananth, D. A., Nambirajan, G., Sivasudha, T., Yamini, R., Bera, S., et al. (2018). Antimicrobial activity, cytotoxicity and DNA binding studies of carbon dots. Spectrochimica Acta Part A: Mol. Biomol. Spectrosc. 196, 295-302. doi:10.1016/j.saa.2018.02.030

Jiang, K., Sun, S., Zhang, L., Lu, Y., Wu, A., Cai, C., et al. (2015). Red, green, and blue luminescence by carbon dots: full-color emission tuning and multicolor cellular imaging. Angew. Chem. Int. Ed. Engl. 54 (18), 5360-5363. doi:10.1002/ anie. 201501193

Jiang, K., Feng, X., Gao, X., Wang, Y., Cai, C., Li, Z., et al. (2019). Preparation of multicolor photoluminescent carbon dots by tuning surface states. Nanomaterials 9 (4), 529-612. doi:10.3390/nano9040529

Jijie, R., Barras, A., Bouckaert, J., Dumitrascu, N., Szunerits, S., and Boukherroub, R. (2018). Enhanced antibacterial activity of carbon dots functionalized with ampicillin combined with visible light triggered photodynamic effects, Colloids Surf. B Biointerfaces, 170. 347-354. doi:10.1016/j.colsurfb.2018.06.040

Jing, P., Han, D., Li, D., Zhou, D., Shen, D., Xiao, G., et al. (2019). Surface related intrinsic luminescence from carbon nanodots: solvent dependent piezochromism. Nanoscale Horiz 4 (1), 175-181. doi:10.1039/c8nh00258d

Kakazey, M., Vlasova, M., Gómez-Vidales, V., Ángeles-Pascual, A., and Basiuk, V. A. (2017). Formation of carbon nanodots with different spin states in mechanically processed mixtures of $\mathrm{ZnO}$ with carbon nanoparticles: an electron paramagnetic resonance study. Phys. Chem. Chem. Phys. 19 (5), 3670-3678. doi:10.1039/c6cp07685h

Kang, Y.-F., Li, Y.-H., Fang, Y.-W., Xu, Y., Wei, X.-M., and Yin, X.-B. (2015). Carbon quantum dots for zebrafish fluorescence imaging. Sci. Rep. 5, 1-12. doi:10.1038/srep11835

Kashani, H. M., Madrakian, T., Afkhami, A., Mahjoubi, F., and Moosavi, M. A. (2019). Bottom-up and green-synthesis route of amino functionalized graphene quantum dot as a novel biocompatible and label-free fluorescence probe for in vitro cellular imaging of human ACHN cell lines. Mater. Sci. Eng. B 251, 114452. doi:10.1016/j.mseb.2019.114452

Kavitha, T., and Kumar, S. (2018). Turning date palm fronds into biocompatible mesoporous fluorescent carbon dots. Sci. Rep. 8 (1), 1-10. doi:10.1038/s41598018-34349-z

Khan, S., Gupta, A., Verma, N. C., and Nandi, C. K. (2015). Time-resolved emission reveals ensemble of emissive states as the origin of multicolor fluorescence in carbon dots. Nano Lett. 15 (12), 8300-8305. doi:10.1021/acs. nanolett.5b03915

Khan, Z. M. S. H., Rahman, R. S., ShumailaIslam, S., and Zulfequar, M. (2019). Hydrothermal treatment of red lentils for the synthesis of fluorescent carbon quantum dots and its application for sensing Fe3+. Opt. Mater. 91, 386-395. doi:10.1016/j.optmat.2019.03.054

Kumar, A., Chowdhuri, A. R., Laha, D., Mahto, T. K., Karmakar, P., and Sahu, S. K. (2017). Green synthesis of carbon dots from Ocimum sanctum for effective fluorescent sensing of $\mathrm{Pb} 2+$ ions and live cell imaging. Sensors Actuators B: Chem. 242, 679-686. doi:10.1016/j.snb.2016.11.109

Kumar, G., Roy, R., Sen, D., Ghorai, U. K., Thapa, R., Mazumder, N., Chattopadhyay, K., et al. (2014). Amino-functionalized graphene quantum dots: origin of tunable heterogeneous photoluminescence. Nanoscale 6 (6), 3384-3391. doi:10.1039/c3nr05376h

Lakshmanan, A., Surendran, P., Manivannan, N., Sathish, M., Balalakshmi, C., Suganthy, N., Rameshkumar, P., Kaviyarasu, K., Ramalingam, G, et al. (2021). Superficial preparation of biocompatible carbon quantum dots for antimicrobial applications. Mater. Today Proc. 36, 171-174. doi:10.1016/j. matpr.2020.02.694

Li, H., Huang, J., Song, Y., Zhang, M., Wang, H., Lu, F., et al. (2018). Degradable carbon dots with broad-spectrum antibacterial activity. ACS Appl. Mater. Inter. 10 (32), 26936-26946. doi:10.1021/acsami.8b08832

Li, H., Kang, Z., Liu, Y., and Lee, S.-T. (2012). Carbon nanodots: synthesis, properties and applications. J. Mater. Chem. 22 (46), 24230-24253. doi:10. $1039 / \mathrm{c} 2 \mathrm{jm} 34690 \mathrm{~g}$ 
Li, L.-S., Jiao, X.-Y., Zhang, Y., Cheng, C., Huang, K., and Xu, L. (2018). Green synthesis of fluorescent carbon dots from Hongcaitai for selective detection of hypochlorite and mercuric ions and cell imaging. Sensors Actuators B: Chem. 263, 426-435. doi:10.1016/j.snb.2018.02.141

Li, L., Wang, X., Fu, Z., and Cui, F. (2017). One-step hydrothermal synthesis of nitrogen- and sulfur-co-doped carbon dots from ginkgo leaves and application in biology. Mater. Lett. 196, 300-303. doi:10.1016/j.matlet.2017.03.112

Li, W., Liu, Y., Wang, B., Song, H., Liu, Z., Lu, S., et al. (2019). Kilogram-scale synthesis of carbon quantum dots for hydrogen evolution, sensing and bioimaging. Chin. Chem. Lett. 30, 2323-2327. doi:10.1016/j.cclet.2019.06.040

Lin, Z., Xue, W., Chen, H., and Lin, J. M. (2012). Classical oxidant induced chemiluminescence of fluorescent carbon dots. Chem. Commun. (Camb) 48 (7), 1051-1053. doi:10.1039/c1cc15290d

Liu, H., Ding, J., Zhang, K., and Ding, L. (2019). Construction of biomass carbon dots based fluorescence sensors and their applications in chemical and biological analysis. Trac Trends Anal. Chem. 118, 315-337. doi:10.1016/j.trac.2019.05.051

Liu, M., Xu, Y., Niu, F., Gooding, J. J., and Liu, J. (2016). Carbon quantum dots directly generated from electrochemical oxidation of graphite electrodes in alkaline alcohols and the applications for specific ferric ion detection and cell imaging. Analyst 141 (9), 2657-2664. doi:10.1039/c5an02231b

Liu, M. L., Chen, B. B., Li, C. M., and Huang, C. Z. (2019). Carbon dots: synthesis, formation mechanism, fluorescence origin and sensing applications. Green. Chem. 21 (3), 449-471. doi:10.1039/c8gc02736f

Liu, W., Diao, H., Chang, H., Wang, H., Li, T., and Wei, W. (2017). Green synthesis of carbon dots from rose-heart radish and application for Fe3+ detection and cell imaging. Sensors Actuators B: Chem. 241, 190-198. doi:10.1016/j.snb.2016.10.068

Liu, Y., Zhao, Y., and Zhang, Y. (2014). One-step green synthesized fluorescent carbon nanodots from bamboo leaves for copper(II) ion detection. Sensors Actuators B: Chem. 196, 647-652. doi:10.1016/j.snb.2014.02.053

Lu, W., Gong, X., Nan, M., Liu, Y., Shuang, S., and Dong, C. (2015). Comparative study for $\mathrm{N}$ and $\mathrm{S}$ doped carbon dots: synthesis, characterization and applications for $\mathrm{Fe}(3+)$ probe and cellular imaging. Anal. Chim. Acta 898, 116-127. doi:10.1016/j.aca.2015.09.050

Ma, H., Sun, C., Xue, G., Wu, G., Zhang, X., Han, X., et al. (2019). Facile synthesis of fluorescent carbon dots from Prunus cerasifera fruits for fluorescent ink, Fe3+ ion detection and cell imaging. Spectrochimica Acta Part A: Mol. Biomol. Spectrosc. 213, 281-287. doi:10.1016/j.saa.2019.01.079

Mehta, V. N., Jha, S., Basu, H., Singhal, R. K., and Kailasa, S. K. (2015). One-step hydrothermal approach to fabricate carbon dots from apple juice for imaging of mycobacterium and fungal cells. Sensors Actuators B: Chem. 213, 434-443. doi:10.1016/j.snb.2015.02.104

Meng, W., Bai, X., Wang, B., Liu, Z., Lu, S., and Yang, B. (2019). Biomass-derived carbon dots and their applications. Energy Environ. Mater. 2 (3), 172-192. doi:10.1002/eem2.12038

Mohammadinejad, R., Dadashzadeh, A., Moghassemi, S., Ashrafizadeh, M., Dehshahri, A., Pardakhty, A., et al. (2019). Shedding light on gene therapy: carbon dots for the minimally invasive image-guided delivery of plasmids and noncoding RNAs - a review, J. Adv. Res., 18, 81-93. doi:10.1016/j.jare.2019.01.004

Moradi, S., Sadrjavadi, K., Farhadian, N., Hosseinzadeh, L., and Shahlaei, M. (2018). Easy synthesis, characterization and cell cytotoxicity of green nano carbon dots using hydrothermal carbonization of Gum Tragacanth and chitosan bio-polymers for bioimaging. J. Mol. Liquids 259, 284-290. doi:10. 1016/j.molliq.2018.03.054

Murugan, N., and Sundramoorthy, A. K. (2018). Green synthesis of fluorescent carbon dots from Borassus flabellifer flowers for label-free highly selective and sensitive detection of Fe3+ ions. New J. Chem. 42 (16), 13297-13307. doi:10.1039/c8nj01894d

Naik, V. M., Gunjal, D. B., Gore, A. H., Pawar, S. P., Mahanwar, S. T., Anbhule, P. V., et al. (2018). Quick and low cost synthesis of sulphur doped carbon dots by simple acidic carbonization of sucrose for the detection of Fe3+ ions in highly acidic environment. Diamond Relat. Mater. 88, 262-268. doi:10.1016/j. diamond.2018.07.018

Ogi, T., Aishima, K., Permatasari, F. A., Iskandar, F., Tanabe, E., and Okuyama, K. (2016). Kinetics of nitrogen-doped carbon dot formation via hydrothermal synthesis. New J. Chem. 40 (6), 5555-5561. doi:10.1039/c6nj00009f

Papaioannou, N., Titirici, M. M., and Sapelkin, A. (2019). Investigating the effect of reaction time on carbon dot formation, structure, and optical properties. ACS Omega 4 (26), 21658-21665. doi:10.1021/acsomega. $9 \mathrm{~b} 01798$
Park, Y., Yoo, J., Lim, B., Kwon, W., and Rhee, S.-W. (2016). Improving the functionality of carbon nanodots: doping and surface functionalization. J. Mater. Chem. A. 4 (30), 11582-11603. doi:10.1039/c6ta04813g

Pooja, D., Singh, L., Thakur, A., and Kumar, P. (2019). Green synthesis of glowing carbon dots from Carica papaya waste pulp and their application as a labelfreechemo probe for chromium detection in water. Sensors Actuators, B Chem. 283, 363-372. doi:10.1016/j.snb.2018.12.027

Pierrat, P., Wang, R., Kereselidze, D., Lux, M., Didier, P., Kichler, A., et al. (2015). Efficient in vitro and in vivo pulmonary delivery of nucleic acid by carbon dot-based nanocarriers. Biomaterials 51, 290-302. doi:10.1016/j.biomaterials.2015.02.017

Pourreza, N., and Ghomi, M. (2019). Green synthesized carbon quantum dots from Prosopis juliflora leaves as a dual off-on fluorescence probe for sensing mercury (II) and chemet drug, Mater. Sci. Eng. C, 98, 887-896. doi:10.1016/j.msec.2018.12.141

Praneerad, J., Neungnoraj, K., In, I., and In, P. (2019). Environmentally friendly supercapacitor based on carbon dots from durian peel as an electrode. Kem 803, 115-119. doi:10.4028/www.scientific.net/KEM.803.115

Prasannan, A., and Imae, T. (2013). One-pot synthesis of fluorescent carbon dots from orange waste peels. Ind. Eng. Chem. Res. 52 (44), 15673-15678. doi:10. 1021/ie402421s

Privitera, A., Righetto, M., Mosconi, D., Lorandi, F., Isse, A. A., Moretto, A., et al. (2016). Boosting carbon quantum dots/fullerene electron transfer via surface group engineering. Phys. Chem. Chem. Phys. 18 (45), 31286-31295. doi:10. 1039/c6cp05981c

Qu, J., Luo, C., Zhang, Q., Cong, Q., and Yuan, X. (2013). Easy synthesis of graphene sheets from alfalfa plants by treatment of nitric acid. Mater. Sci. Eng. B 178 (6), 380-382. doi:10.1016/j.mseb.2013.01.016

Radnia, F., Mohajeri, N., and Zarghami, N. (2020). New insight into the engineering of green carbon dots: possible applications in emerging cancer theranostics, Talanta, 209, 120547. doi:10.1016/j.talanta.2019.120547

Raina, S., Thakur, A., Sharma, A., Pooja, D., and Minhas, A. P. (2020). Bactericidal activity of Cannabis sativa phytochemicals from leaf extract and their derived carbon dots and Ag@carbon dots. Mater. Lett. 262, 127122. doi:10.1016/j. matlet.2019.127122

Ramezani, Z., Qorbanpour, M., and Rahbar, N. (2018). Green synthesis of carbon quantum dots using quince fruit (Cydonia oblonga) powder as carbon precursor: application in cell imaging and As3+ determination, Colloids Surf. A: Physicochemical Eng. Aspects, 549, 58-66. doi:10.1016/j. colsurfa.2018.04.006

Raveendran, V., Suresh Babu, A. R., and Renuka, N. K. (2019). Mint leaf derived carbon dots for dual analyte detection of Fe(iii) and ascorbic acid. RSC Adv. 9 (21), 12070-12077. doi:10.1039/c9ra02120e

Reiss, P., Carrière, M., Lincheneau, C., Vaure, L., and Tamang, S. (2016). Synthesis of semiconductor nanocrystals, focusing on nontoxic and earth-abundant materials. Chem. Rev. 116 (18), 10731-10819. doi:10.1021/acs.chemrev. 6b00116

Ren, G., Tang, M., Chai, F., and Wu, H. (2018). One-pot synthesis of highly fluorescent carbon dots from spinach and multipurpose applications. Eur. J. Inorg. Chem. 2018 (2), 153-158. doi:10.1002/ejic.201701080

Reyes, D., Camacho, M., Camacho, M., Mayorga, M., Weathers, D., Salamo, G., et al. (2016). Laser ablated carbon nanodots for light emission. Nanoscale Res. Lett. 11 (1), 424. doi:10.1186/s11671-016-1638-8

Ribeiro, M., Simões, L. C., and Simões, M. (2018). Biocides. Encycl. Microbiol. 487-490. doi:10.1016/B978-0-12-809633-8.12118-1

Rong, M.-C., Zhang, K.-X., Wang, Y.-R., and Chen, X. (2017). The synthesis of B, $\mathrm{N}$-carbon dots by a combustion method and the application of fluorescence detection for Cu 2+. Chin. Chem. Lett. 28 (5), 1119-1124. doi:10.1016/j.cclet. 2016.12.009

Sabet, M., and Mahdavi, K. (2019). Green synthesis of high photoluminescence nitrogen-doped carbon quantum dots from grass via a simple hydrothermal method for removing organic and inorganic water pollutions. Appl. Surf. Sci. 463, 283-291. doi:10.1016/j.apsusc.2018.08.223

Sachdev, A., and Gopinath, P. (2015). Green synthesis of multifunctional carbon dots from coriander leaves and their potential application as antioxidants, sensors and bioimaging agents. Analyst 140 (12), 4260-4269. doi:10.1039/ c5an00454c

Sagbas, S., and Sahiner, N. (2019). Carbon dots: preparation, properties, and application, Nanocarbon and its Composites. Elsevier Ltd. doi:10.1016/B9780-08-102509-3.00022-5 
Saheeda, P., Sabira, K., Joseph, J., and Jayaleksmi, S. (2019). Green chemistry route to realize, high quantum yield carbon quantum dots for cellular imaging applications. Mater. Res. Express 6 (7), 075025. doi:10.1088/2053-1591/ab1450

Sahu, S., Behera, B., Maiti, T. K., and Mohapatra, S. (2012). Simple one-step synthesis of highly luminescent carbon dots from orange juice: application as excellent bio-imaging agents. Chem. Commun. (Camb) 48 (70), 8835-8837. doi:10.1039/c2cc33796g

Sarkar, S., Banerjee, D., Ghorai, U. K., Das, N. S., and Chattopadhyay, K. K. (2016). Size dependent photoluminescence property of hydrothermally synthesized crystalline carbon quantum dots. J. Lumin. 178, 314-323. doi:10.1016/j.jlumin. 2016.05.033

Sarkar, T., Bohidar, H. B., and Solanki, P. R. (2018). Carbon dots-modified chitosan based electrochemical biosensing platform for detection of vitamin D. Int. J. Biol. Macromol. 109, 687-697. doi:10.1016/j.ijbiomac.2017.12.122

Sarswat, P. K., and Free, M. L. (2015). Light emitting diodes based on carbon dots derived from food, beverage, and combustion wastes. Phys. Chem. Chem. Phys. 17 (41), 27642-27652. doi:10.1039/c5cp04782j

Sciortino, A., Cannizzo, A., and Messina, F. (2018). Carbon nanodots: a review-from the current understanding of the fundamental photophysics to the full control of the optical response. J. Carbon Res. 4 (4), 67. doi:10.3390/c4040067

Sendão, R., Yuso, M. d. V. M. d., Algarra, M., Esteves da Silva, J. C. G., and Pinto da Silva, L. (2020). Comparative life cycle assessment of bottom-up synthesis routes for carbon dots derived from citric acid and urea. J. Clean. Prod. 254, 120080-120090. doi:10.1016/j.jclepro.2020.120080

Sevilla, M., and Fuertes, A. B. (2009). The production of carbon materials by hydrothermal carbonization of cellulose. Carbon 47 (9), 2281-2289. doi:10. 1016/j.carbon.2009.04.026

Shahidi, S., Rashidian, M., and Dorranian, D. (2018). Preparation of antibacterial textile using laser ablation method. Opt. Laser Technology 99, 145. doi:10.1016/j. optlastec.2017.08.025

Shahshahanipour, M., Rezaei, B., Ensafi, A. A., and Etemadifar, Z. (2019). An ancient plant for the synthesis of a novel carbon dot and its applications as an antibacterial agent and probe for sensing of an anti-cancer drug. Mater. Sci. Eng. C 98, 826-833. doi:10.1016/j.msec.2019.01.041

Shen, J., Shang, S., Chen, X., Wang, D., and Cai, Y. (2017). Facile synthesis of fluorescence carbon dots from sweet potato for $\mathrm{Fe} 3+$ sensing and cell imaging. Mater. Sci. Eng. C 76, 856-864. doi:10.1016/j.msec.2017.03.178

Shivaji, K., Mani, S., Ponmurugan, P., De Castro, C. S., Lloyd Davies, M., Balasubramanian, M. G., et al. (2018). Green-synthesis-derived cds quantum dots using tea leaf extract: antimicrobial, bioimaging, and therapeutic applications in lung cancer cells. ACS Appl. Nano Mater. 1 (4), 1683-1693. doi:10.1021/acsanm.8b00147

Singh, R. K., Kumar, R., Singh, D. P., Savu, R., and Moshkalev, S. A. (2019). Progress in microwave-assisted synthesis of quantum dots (graphene/carbon/ semiconducting) for bioapplications: a review. Mater. Today Chem. 12, 282-314. doi:10.1016/j.mtchem.2019.03.001

Song, X., Guo, Q., Cai, Z., Qiu, J., and Dong, G. (2019). Synthesis of multi-color fluorescent carbon quantum dots and solid state CQDs@SiO2 nanophosphors for light-emitting devices. Ceramics Int. 45 (14), 17387-17394. doi:10.1016/j. ceramint.2019.05.299

Su, H., Bi, Z., Ni, Y., and Yan, L. (2019). One-pot degradation of cellulose into carbon dots and organic acids in its homogeneous aqueous solution. Green. Energ. Environ. 4 (4), 391-399. doi:10.1016/j.gee.2019.01.009

$\mathrm{Su}$, Q., Gan, L., Liu, J., and Yang, X. (2020). Carbon dots derived from pea for specifically binding with Cryptococcus neoformans. Anal. Biochem. 589, 113476. doi:10.1016/j.ab.2019.113476

Sumanth Kumar, D., Jai Kumar, B., and Mahesh, H. M. (2018). Quantum nanostructures (qds): an overview. Synth. Inorg. Nanomater., 59. doi:10. 1016/B978-0-08-101975-7.00003-8

Sun, X., He, J., Yang, S., Zheng, M., Wang, Y., Ma, S., et al. (2017). Green synthesis of carbon dots originated from Lycii Fructus for effective fluorescent sensing of ferric ion and multicolor cell imaging. J. Photochem. Photobiol. B, Biol. 175, 219-225. doi:10.1016/j.jphotobiol.2017.08.035

Tan, H. L., Sanira Putri, M. K., Idris, S. S., Hartikainen, N., Abu Bakar, N. F., Keirouz, A., et al. (2020). High-throughput fabrication of carbonized electrospun polyacrylonitrile/poly(acrylic acid) nanofibers with additives for enhanced electrochemical sensing. J. Appl. Polym. Sci. 137, 49341-49343. doi:10.1002/app.49341
Tan, M., Zhang, L., Tang, R., Song, X., Li, Y., Wu, H., et al. (2013). Enhanced photoluminescence and characterization of multicolor carbon dots using plant soot as a carbon source. Talanta 115, 950-956. doi:10.1016/j.talanta.2013.06.061

Tan, X. W., Romainor, A. N. B., Chin, S. F., and Ng, S. M. (2014). Carbon dots production via pyrolysis of sago waste as potential probe for metal ions sensing. J. Anal. Appl. Pyrolysis 105, 157-165. doi:10.1016/j.jaap.2013.11.001

Tang, D., Liu, J., Wu, X., Liu, R., Han, X., Han, Y., et al. (2014). Carbon quantum dot/NiFe layered double-hydroxide composite as a highly efficient electrocatalyst for water oxidation. ACS Appl. Mater. Inter. 6 (10), 7918-7925. doi:10.1021/am501256x

Thakur, A., Devi, P., Saini, S., Jain, R., Sinha, R. K., and Kumar, P. (2019). Citrus limetta organic waste recycled carbon nanolights: photoelectro catalytic, sensing, and biomedical applications. ACS Sustainable Chem. Eng. 7 (1), 502-512. doi:10.1021/acssuschemeng.8b04025

Tian, Z., Zhang, X., Li, D., Zhou, D., Jing, P., Shen, D., et al. (2017). Full-color inorganic carbon dot phosphors for white-light-emitting diodes. Adv. Opt. Mater. 5, 1700416-1700419. doi:10.1002/adom.201700416

Tibodee, A., Hirunpinyopas, W., Jeamjumnunja, K., and Sirisaksoontorn, W. (2020). Synthesis of carbon dots from the biomass products for supercapacitor applications. IOP Conf. Ser. Mater. Sci. Eng. 773 (1), 012022-012027. doi:10.1088/1757-899X/773/1/012022

Thambiraj, S., and Ravi Shankaran, D. Green synthesis of highly fluorescent carbon quantum dots from sugarcane bagasse pulp. Appl. Surf. Sci. 390, 435-443. (2016). doi:10.1016/j.apsusc.2016.08.106

Vandarkuzhali, S. A. A., Jeyalakshmi, V., Sivaraman, G., Singaravadivel, S., Krishnamurthy, K. R., and Viswanathan, B. (2017). Highly fluorescent carbon dots from Pseudo-stem of banana plant: applications as nanosensor and bio-imaging agents. Sensors Actuators B: Chem. 252, 894-900. doi:10.1016/j.snb.2017.06.088

Vasimalai, N., Vilas-Boas, V., Gallo, J., Cerqueira, M. F., Menéndez-Miranda, M., Costa-Fernández, J. M., et al. (2018). Green synthesis of fluorescent carbon dots from spices for in vitro imaging and tumour cell growth inhibition. Beilstein J. Nanotechnol. 9 (1), 530-544. doi:10.3762/bjnano.9.51

Vaz, R., Bettini, J., Júnior, J. G. F., Lima, E. D. S., Botero, W. G., Santos, J. C. C., et al. (2017). High luminescent carbon dots as an eco-friendly fluorescence sensor for $\mathrm{Cr}(\mathrm{VI})$ determination in water and soil samples. J. Photochem. Photobiol. A: Chem. 346, 502-511. doi:10.1016/ j.jphotochem.2017.06.047

Wan, Y., Wang, M., Zhang, K., Fu, Q., Gao, M., Wang, L., et al. (2019). Facile and green synthesis of fluorescent carbon dots from the flowers of Abelmoschus manihot (Linn.) Medicus for sensitive detection of 2,4,6-trinitrophenol and cellular imaging. Microchemical J. 148, 385-396. doi:10.1016/j.microc.2019.05.026

Wang, C., Shi, H., Yang, M., Yan, Y., Liu, E., Ji, Z., et al. (2020). Facile synthesis of novel carbon quantum dots from biomass waste for highly sensitive detection of iron ions. Mater. Res. Bull. 124, 110730. doi:10.1016/j.materresbull.2019.110730

Wang, J., Wang, C. F., and Chen, S. (2012). Amphiphilic egg-derived carbon dots: rapid plasma fabrication, pyrolysis process, and multicolor printing patterns. Angew. Chem. Int. Ed. Engl. 51, 9297-9301. doi:10.1002/anie.201204381

Wang, K., Ji, Q., Li, H., Guan, F., Zhang, D., Feng, H., et al. (2017). Synthesis and antibacterial activity of silver@carbon nanocomposites. J. Inorg. Biochem. 166, 64-67. doi:10.1016/j.jinorgbio.2016.11.002

Wang, K., Ji, Q., Xu, J., Li, H., Zhang, D., Liu, X., et al. (2018). Highly sensitive and selective detection of amoxicillin using carbon quantum dots derived from beet. J. Fluoresc. 28 (3), 759-765. doi:10.1007/s10895-018-2237-0

Wang, L., Bi, Y., Hou, J., Li, H., Xu, Y., Wang, B., et al. (2016). Facile, green and clean one-step synthesis of carbon dots from wool: application as a sensor for glyphosate detection based on the inner filter effect. Talanta 160, 268-275. doi:10.1016/j.talanta.2016.07.020

Wang, N., Fan, H., Sun, J., Han, Z., Dong, J., and Ai, S. (2016). Fluorine-doped carbon nitride quantum dots: ethylene glycol-assisted synthesis, fluorescent properties, and their application for bacterial imaging. Carbon 109, 141-148. doi:10.1016/j.carbon.2016.08.004

Wang, S., Cole, I. S., Zhao, D., and Li, Q. (2016). The dual roles of functional groups in the photoluminescence of graphene quantum dots. Nanoscale 8 (14), 7449-7458. doi:10.1039/c5nr07042b

Wang, T., Zhai, Y., Zhu, Y., Li, C., and Zeng, G. (2018). A review of the hydrothermal carbonization of biomass waste for hydrochar formation: process conditions, fundamentals, and physicochemical properties, Renew. Sustainable Energ. Rev., 90. 223-247. doi:10.1016/j.rser.2018.03.071 
Wang, Y., and Hu, A. (2014). Carbon quantum dots: synthesis, properties and applications. J. Mater. Chem. C 2, 6921-6939. doi:10.1039/C4TC00988F

Wu, Q., Li, W., Wu, P., Li, J., Liu, S., Jin, C., et al. (2015). Effect of reaction temperature on properties of carbon nanodots and their visible-light photocatalytic degradation of tetracyline. RSC Adv. 5 (92), 75711-75721. doi:10.1039/c5ra16080d

Xiong, Y., Schneider, J., Reckmeier, C. J., Huang, H., Kasák, P., and Rogach, A. L. (2017). Carbonization conditions influence the emission characteristics and the stability against photobleaching of nitrogen doped carbon dots. Nanoscale 9 (32), 11730-11738. doi:10.1039/c7nr03648e

Xu, X., Ray, R., Gu, Y., Ploehn, H. J., Gearheart, L., Raker, K., et al. (2004). Electrophoretic analysis and purification of fluorescent single-walled carbon nanotube fragments. J. Am. Chem. Soc. 126 (40), 12736-12737. doi:10.1021/ ja040082h

Yadav, P. K., Singh, V. K., Chandra, S., Bano, D., Kumar, V., Talat, M., et al. (2019). Green synthesis of fluorescent carbon quantum dots from Azadirachta indica leaves and their peroxidase-mimetic activity for the detection of $\mathrm{H} 2 \mathrm{O} 2$ and ascorbic acid in common fresh fruits. ACS Biomater. Sci. Eng. 5 (2), 623-632. doi:10.1021/acsbiomaterials.8b01528

Yang, S., Wang, K., Wang, X., and Sun, X. (2020). Organic acid participation strategy for the synthesis of highly fluorescent carbon dots and their application in dual-mode determination of copper ions. Appl. Surf. Sci. 505, 144567. doi:10. 1016/j.apsusc.2019.144567

Yang, X., Zhuo, Y., Zhu, S., Luo, Y., Feng, Y., and Dou, Y. (2014). Novel and green synthesis of high-fluorescent carbon dots originated from honey for sensing and imaging. Biosens. Bioelectron. 60, 292-298. doi:10.1016/j.bios. 2014.04.046

Yao, B., Huang, H., Liu, Y., and Kang, Z. (2019). Carbon dots: a small conundrum. Trends Chem. 1 (2), 235-246. doi:10.1016/j.trechm.2019.02.003

Yatom, S., Bak, J., Khrabryi, A., and Raitses, Y. (2017). Detection of nanoparticles in carbon arc discharge with laser-induced incandescence. Carbon 117, 154-162. doi:10.1016/j.carbon.2017.02.055

Ye, R., Peng, Z., Metzger, A., Lin, J., Mann, J. A., Huang, K., et al. (2015). Bandgap engineering of coal-derived graphene quantum dots. ACS Appl. Mater. Inter. 7 (12), 7041-7048. doi:10.1021/acsami.5b01419

Yi, C., Pan, Y., and Fang, Y. (2019). Surface engineering of carbon nanodots (C-dots) for biomedical applications. Novel nanomaterials for biomedical, Environmental and Energy Applications, Amsterdam: Elsevier Inc. 137-188. doi:10.1016/B978-0-12-814497-8.00005-9

Yu, H., Li, X., Zeng, X., and Lu, Y. (2016). Preparation of carbon dots by nonfocusing pulsed laser irradiation in toluene. Chem. Commun. (Camb) 52 (4), 819-822. doi:10.1039/c5cc08384b

Yuan, M., Zhong, R., Gao, H., Li, W., Yun, X., Liu, J., et al. (2015). One-step, green, and economic synthesis of water-soluble photoluminescent carbon dots by hydrothermal treatment of wheat straw, and their bio-applications in labeling, imaging, and sensing. Appl. Surf. Sci. 355, 1136-1144. doi:10.1016/j.apsusc. 2015.07.095

Zhan, J., Geng, B., Wu, K., Xu, G., Wang, L., Guo, R., et al. (2018). A solventengineered molecule fusion strategy for rational synthesis of carbon quantum dots with multicolor bandgap fluorescence. Carbon 130, 153-163. doi:10.1016/j. carbon.2017.12.075

Zhang, H., Wang, Y., Liu, P., Li, Y., Yang, H. G., An, T., et al. (2015). A fluorescent quenching performance enhancing principle for carbon nanodot-sensitized aqueous solar cells. Nano Energy 13, 124-130. doi:10.1016/j.nanoen.2015.01.046

Zhang, J., and Yu, S.-H. (2016). Carbon dots: large-scale synthesis, sensing and bioimaging. Mater. Today 19 (7), 382-393. doi:10.1016/j.mattod.2015. 11.008

Zhang, J., Yuan, Y., Liang, G., and Yu, S.-H. (2015). Scale-up synthesis of fragrant nitrogen-doped carbon dots from bee pollens for bioimaging and catalysis. Adv. Sci. 2, 1500002-1500004. doi:10.1002/advs.201500002

Zhang, K., Shi, Y., Jia, Y., Li, P., Zhang, X., Feng, X., et al. (2020). Tunable dual fluorescence emissions with high photoluminescence quantum yields modulated by $\mathrm{Na}$ ion dispersion method for purely solid state $\mathrm{N}$-doped carbon dots. J. Photochem. Photobiol. A: Chem. 397, 112548. doi:10.1016/j. jphotochem.2020.112548

Zhang, S., Zhang, L., Huang, L., Zheng, G., Zhang, P., Jin, Y., et al. (2019). Study on the fluorescence properties of carbon dots prepared via combustion process. J. Lumin. 206, 608-612. doi:10.1016/j.jlumin.2018.10.086
Zhang, Y., Gao, Z., Zhang, W., Wang, W., Chang, J., and Kai, J. (2018). Fluorescent carbon dots as nanoprobe for determination of lidocaine hydrochloride. Sensors Actuators B: Chem. 262, 928-937. doi:10.1016/j.snb.2018.02.079

Zhang, Y., Wang, Y., Feng, X., Zhang, F., Yang, Y., and Liu, X. (2016). Effect of reaction temperature on structure and fluorescence properties of nitrogendoped carbon dots. Appl. Surf. Sci. 387, 1236-1246. doi:10.1016/j.apsusc.2016. 07.048

Zhang, Z., Pan, Y., Fang, Y., Zhang, L., Chen, J., and Yi, C. (2016). Tuning photoluminescence and surface properties of carbon nanodots for chemical sensing. Nanoscale 8 (1), 500-507. doi:10.1039/c5nr06534h

Zhao, A., Chen, Z., Zhao, C., Gao, N., Ren, J., and Qu, X. (2015). Recent advances in bioapplications of C-dotsCarbon, December: Elsevier, 309-327. doi:10.1016/j. carbon.2014.12.045

Zhao, C., Jiao, Y., Zhang, L., and Yang, Y. (2018). One-step synthesis of S,B codoped carbon dots and their application for selective and sensitive fluorescence detection of diethylstilbestrol. New J. Chem. 42 (4), 2857-2864. doi:10.1039/ c7nj04983h

Zhao, C., Li, X., Cheng, C., and Yang, Y. (2019). Green and microwave-assisted synthesis of carbon dots and application for visual detection of cobalt(II) ions and pH sensing, Microchemical J., 147. 183-190. doi:10.1016/j.microc.2019. 03.029

Zhao, X., Liao, S., Wang, L., Liu, Q., and Chen, X. (2019). Facile green and one-pot synthesis of purple perilla derived carbon quantum dot as a fluorescent sensor for silver ion, Talanta, 201. 1-8. doi:10.1016/j.talanta.2019.03.095

Zhi, B., Gallagher, M. J., Frank, B. P., Lyons, T. Y., Qiu, T. A., Da, J., et al. (2018). Investigation of phosphorous doping effects on polymeric carbon dots: fluorescence, photostability, and environmental impact. Carbon 129, 438-449. doi:10.1016/j.carbon.2017.12.004

Zhong, Y., Li, J., Jiao, Y., Zuo, G., Pan, X., Su, T., et al. (2017). One-step synthesis of orange luminescent carbon dots for $\mathrm{Ag}+$ sensing and cell imaging. J. Lumin. 190, 188-193. doi:10.1016/j.jlumin.2017.05.057

Zhou, J., Shan, X., Ma, J., Gu, Y., Qian, Z., Chen, J., et al. (2014). Facile synthesis of P-doped carbon quantum dots with highly efficient photoluminescence. RSC Adv. 4 (11), 5465-5468. doi:10.1039/c3ra45294h

Zhou, Y., Desserre, A., Sharma, S. K., Li, S., Marksberry, M. H., Chusuei, C. C., et al. (2017). Gel-like carbon dots: characterization and their potential applications. ChemPhysChem 18 (8), 890-897. doi:10.1002/cphc. 201700038

Zhu, J., Bai, X., Chen, X., Shao, H., Zhai, Y., Pan, G., et al. (2019). Spectrally tunable solid state fluorescence and room-temperature phosphorescence of carbon dots synthesized via seeded growth method. Adv. Opt. Mater. 7 (9), 1801599-1801607.

Zhu, S., Meng, Q., Wang, L., Zhang, J., Song, Y., Jin, H., et al. (2013). Highly photoluminescent carbon dots for multicolor patterning, sensors, and bioimaging. Angew. Chem. Int. Ed. Engl. 52 (14), 3953-3957. doi:10.1002/ anie. 201300519

Zhu, S., Song, Y., Zhao, X., Shao, J., Zhang, J., and Yang, B. (2015). The photoluminescence mechanism in carbon dots (graphene quantum dots, carbon nanodots, and polymer dots): current state and future perspective. Nano Res. 8 (2), 355-381. doi:10.1007/s12274-014-0644-3

Zhu, Z., Cheng, R., Ling, L., Li, Q., and Chen, S. (2020). Rapid and large-scale production of multi-fluorescence carbon dots by a magnetic hyperthermia method. Angew. Chem. Int. Ed. 59 (8), 3099-3105. doi:10.1002/anie.201914331

Zhu, Z., Zhai, Y., Li, Z., Zhu, P., Mao, S., Zhu, C., et al. (2019). Red carbon dots: optical property regulations and applications. Mater. Today 30, 52-79. doi:10. 1016/j.mattod.2019.05.003

Conflict of Interest: The authors declare that the research was conducted in the absence of any commercial or financial relationships that could be construed as a potential conflict of interest.

Copyright (c) 2021 Khairol Anuar, Tan, Lim, So'aib and Abu Bakar. This is an openaccess article distributed under the terms of the Creative Commons Attribution License (CC BY). The use, distribution or reproduction in other forums is permitted, provided the original author(s) and the copyright owner(s) are credited and that the original publication in this journal is cited, in accordance with accepted academic practice. No use, distribution or reproduction is permitted which does not comply with these terms. 